\title{
Sexual antagonism in haplodiploids
}

\author{
Thomas J. Hitchcock, ${ }^{1,2}$ iD Andy Gardner, ${ }^{1}$ iD and Laura Ross ${ }^{3}$ iD \\ ${ }^{1}$ School of Biology, University of St Andrews, St. Andrews, United Kingdom \\ ${ }^{2}$ E-mail: th76@st-andrews.ac.uk \\ ${ }^{3}$ School of Biological Sciences, Institute of Evolutionary Biology, University of Edinburgh, Edinburgh, United Kingdom
}

Received March 29, 2021

Accepted September 27, 2021

Females and males may face different selection pressures, such that alleles conferring a benefit in one sex may be deleterious in the other. Such sexual antagonism has received a great deal of theoretical and empirical attention, almost all of which has focused on diploids. However, a sizeable minority of animals display an alternative haplodiploid mode of inheritance, encompassing both arrhenotoky, whereby males develop from unfertilized eggs, and paternal genome elimination (PGE), whereby males receive but do not transmit a paternal genome. Alongside unusual genetics, haplodiploids often exhibit social ecologies that modulate the relative value of females and males. Here, we develop a series of evolutionary-genetic models of sexual antagonism for haplodiploids, incorporating details of their molecular biology and social ecology. We find that: (1) PGE promotes female-beneficial alleles more than arrhenotoky, and to an extent determined by the timing of elimination-and degree of silencing of-the paternal genome; (2) sib-mating relatively promotes female-beneficial alleles, as do other forms of inbreeding including limited male-dispersal, oedipalmating, and the pseudo-hermaphroditism of Icerya purchasi; (3) resource competition between related females inhibits the invasion of female-beneficial alleles; and (4) sexual antagonism foments conflicts between parents and offspring, endosymbionts and hosts, and maternal- and paternal-origin genes.

KEY WORDS: Arrhenotoky, haplodiploidy, inbreeding, intralocus sexual conflict, paternal genome elimination, sexually antagonistic alleles.

Organisms often appear remarkably well adapted to live the lives they do, as a consequence of the historical action of natural selection. Some of the best tests of our understanding of adaptation occur when organisms must make trade-offs between conflicting design objectives. Sexual antagonism is one such example, whereby genetic variants may prove beneficial to one sex but detrimental to the other. This has motivated a large body of theoretical work considering when such sexually antagonistic alleles will be able to invade (Owen 1953), how this may vary across the genome (Parsons 1961; Kidwell et al. 1977; Pamilo 1979; Rice 1984; Frank and Hurst 1996; Frank and Patten 2020; Hitchcock and Gardner 2020; Klein et al. 2021), and how we may be able to detect such alleles from population genetic data (Cheng and Kirkpatrick 2016; Kasimatis et al. 2019; Ruzicka and Connallon 2020; Ruzicka et al. 2020). This theory has been complemented more recently by molecular and quantitative genetic studies of laboratory and wild populations, both estimating the extent of sexual antagonism, and identifying specific loci at which sexu- ally antagonistic alleles reside (Poissant et al. 2010; Mank 2017; Rowe et al. 2018; Connallon and Matthews 2019).

Almost all this research has focused on diploid, "eumendelian" (sensu Normark 2006) organisms. However, a sizeable minority of animals $(\sim 15 \%)$ display an alternative, haplodiploid mode of inheritance (Normark 2003, 2006; Bachtrog et al. 2014). Haplodiploidy encompasses both arrhenotokywhereby males develop from unfertilized eggs - and paternal genome elimination (PGE) — whereby males receive but do not transmit a paternal genome-and is employed by a diverse cast of creatures in groups as distinct as mites, nematodes, rotifers, springtails, beetles, wasps, and flies. In all of these organisms, males exclusively transmit maternal-origin genes, such that reproduction of females contributes twice as much to the ancestry of future generations as does that of males. While similarities in transmission genetics have drawn comparisons to X-linked genes (Kraaijeveld 2009; de la Filia et al. 2015), haplodiploids are not merely whole-organismal manifestations of $\mathrm{X}$ 
chromosomes. First, mechanisms of dosage compensation - that ensure an equal balance of X-linked versus autosomal gene products between females and males - are understood to play an important role in modulating sexual antagonism in relation to the X chromosome (Hitchcock and Gardner 2020), but it is unclear whether these mechanisms should apply in the same way in relation to arrhenotokous species in which males are haploid across their entire genome, and thus, might be able to achieve dosage compensation either passively, or through other mechanisms (e.g., additional endoreduplication) (Aron et al. 2005; Scholes et al. 2013). Second, although PGE is similar to X-linkage from a transmission perspective, this form of haplodiploidy involves males being somatically diploid through some or all of their lives (Burt and Trivers 2006; Gardner and Ross 2014; Klein et al. 2021), with concomitant gene dosage and dominance effects that may be expected to affect the balance between female- versus male-beneficial alleles.

Moreover, haplodiploids often exhibit characteristic social ecologies, including gregarious broods, chronic inbreeding, and strongly female-biased primary sex ratios (Hamilton 1967). An archetypal example is the date stone beetle (Coccotrypes dactyliperda), whereby a gravid female excavates a tunnel into a date seed and lays a large and heavily female-biased brood, her offspring then mate with each other, and her mated-daughters then leave to search for dates within which to raise their own families (Hamilton 1993; Spennemann 2019). While the particular niche that these species inhabit may vary substantially-from fungal-feeding to sap- or blood-sucking - they often share a similarly viscous population structure, with small, semi-isolated subpopulations, and large amounts of inbreeding (Hamilton 1967, 1978, 1993; Normark 2006). These unusual mating systems generate peculiar patterns of within-individual and betweenindividual relatedness, as well as differences in the scales at which the sexes compete and cooperate. Both of these factors are known to modulate the relative genetic value of males and females in the context of sex allocation (Taylor 1981; Frank 1986b; Nagelkerke and Sabelis 1996; West 2009), and thus, might also be expected to alter the outcome of sexually antagonistic selection.

Here, we investigate how the molecular biology and sexual ecology of haplodiploid organisms modulate the evolution of sexual antagonism, developing a general, theoretical overview, and presenting a series of evolutionary-genetic models to provide concrete illustration. We first consider how the genetic asymmetries found in haplodiploids are expected to alter the fate of sexually antagonistic alleles, and how this is modified by variation in the timing and expression of the paternal genome. We then explore how inbreeding alters these conditions, investigating the effects of sib-mating, lower male-dispersal, oedipal-mating, and the pseudo-hermaphroditism of Icerya purchasi, as well as the ef- fect of local resource competition among females. Finally, we explore how such genetic and ecological asymmetries may foment conflicts over sexual antagonism between parents and offspring, endosymbionts and their hosts, and maternal- and paternal-origin genes.

\section{Genetic Asymmetries THE CONSEQUENCES OF ASYMMETRIC TRANSMISSION}

In most sexual organisms, males and females pass on their maternal- and paternal-origin genes with equal frequency. In contrast, haplodiploid organisms are united by the fact that they break this fundamental symmetry, with males exclusively passing on maternal-origin genes (Normark 2006). The best-known form of this is arrhenotoky, whereby males are haploid, produced from unfertilized eggs, and thus, carry only a maternal-origin genome. Consequently, they are constrained to only ever transmit maternal-origin genes, and do so only to daughters. In another form of haplodiploidy, PGE, males are formed from fertilized eggs, and thus, initially contain both maternal- and paternalorigin genomes. However, either early during development (embryonic PGE) or during spermatogenesis (germline PGE), they eliminate their paternal genome, and thus, their sperm carries only genes of maternal origin (see Fig. 1).

These distinct transmission genetics alter the relative contributions that females and males make to the ancestry of future generations, that is, their reproductive values, which provide the weights upon selective changes occurring within these different classes of individual (Price 1970; Taylor 1990; Grafen 2006). Specifically, if we choose a random gene from the distant future and trace it back to the present generation, the probability $c_{f}$ that it is currently carried by a female defines the class reproductive value of females, and the probability $c_{m}=1-c_{f}$ that it is carried by a male defines the class reproductive value of males. We find that - under the assumption of discrete, nonoverlapping generations - the ratio of these two reproductive values is given by $c_{f} / c_{m}=2(1-L)$, where $L$ is the probability that males transmit their paternal genome. Under conventional diploidy, we have $L=1 / 2$ and, hence, $c_{f} / c_{m}=1$, that is, both sexes make an equal genetic contribution to future generations. In contrast, under haplodiploidy, we have $L=0$ and, hence, $c_{f} / c_{m}=2$, such that females collectively make twice the genetic contribution made by the males. In some haplodiploid species, including mealybugs and body lice, imperfect elimination of the paternalorigin genome has been documented, such that in these species males do occasionally transmit paternal-origin genes, that is, $0<L<1 / 2$ (de la Filia et al. 2018, 2019). As the extent of male paternal transmission $L$ increases, then males obtain an increasing share of the ancestry of future generations (Gardner and Ross 


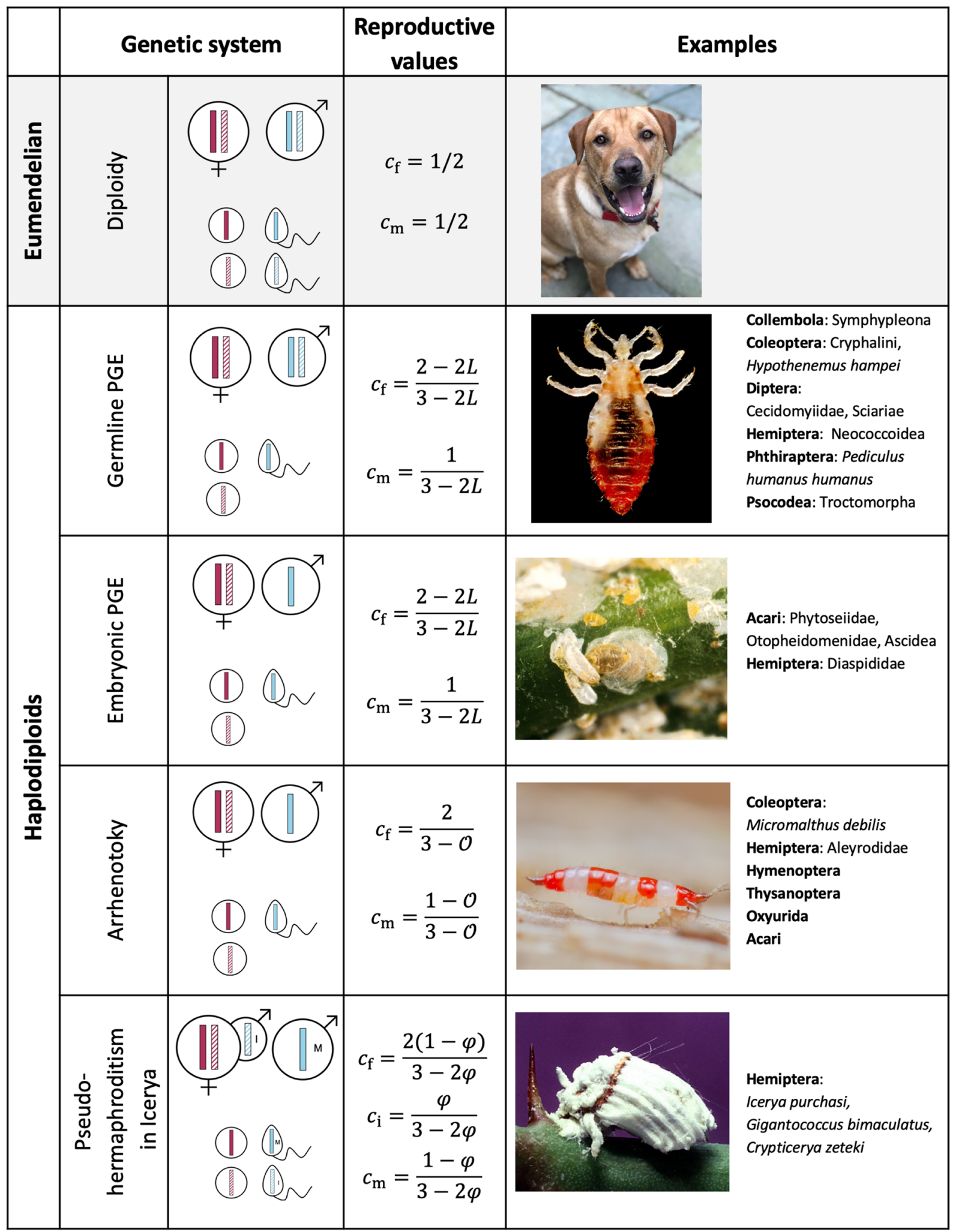

Figure 1. Conceptual description of the different inheritance schemes, and examples of species and groups which fall into these categories, summarized from Gardner and Ross (2014); de la Filia et al. (2015); and Hodson et al. (2017). Solid colors represent maternal-origin genes, and dashed are paternal-origin genes. In PGE systems, $L$ is the degree of paternal genome leakage. Under arrhenotoky, $\mathcal{O}$ is the proportion of oedipal mating. In the Iceryan pseudo-hermaphroditism, $\varphi$ is the proportion of eggs fertilised by the infectious male tissue (I), with $1-\varphi$ the proportion fertilized by true males (M). Images in order from top to bottom: Canis familiaris (Samantha Sturiale), Body louse (public domain), Aulacaspis yasumatsui (Jeffrey W. Lotz, Florida Department of Agriculture and Consumer Services, Bugwood.org), Haplothrips subtilissimus (Andy Murray, chaosofdelight.org), Icerya purchasi (public domain). 
2011; Yeh and Gardner 2012), scaling between the extremes of diplodiploidy and haplodiploidy. This effect of paternal transmission in PGE species can, thus, be thought of as conceptually similar to cases of "paternal leakage" in cytoplasmic elements which also increase the reproductive value of males, and decrease that of females (Rand et al. 2001, Kuijper et al. 2015; Hitchcock and Gardner 2020).

If a sexually antagonistic allele confers a marginal fitness benefit $\sigma$ to one sex, and a marginal fitness $\operatorname{cost} \tau$ to the other, then the condition for a sexually antagonistic variant to invade from rarity will - under weak selection, outbreeding and in the absence of social interactions between relatives-be $c_{f} \sigma>c_{m} \tau$ if the allele is female-beneficial, and $c_{f} \tau<c_{m} \sigma$ if it is male-beneficial (Hitchcock and Gardner 2020). A female-beneficial allele will, therefore, invade under haplodiploidy provided $2 \sigma>\tau$ while it will only invade under diploidy provided $\sigma>\tau$. Accordingly, for a given ratio of benefit and cost, the transmission genetics of haplodiploidy acts to promote the invasion of female-beneficial alleles (and inhibit the invasion of male-beneficial allele), relative to eumendelian diploidy, just as the transmission genetics of X chromosomes does (Frank and Patten 2020; Hitchcock and Gardner 2020; Klein et al. 2021). With imperfect PGE, invasion conditions will be $2(1-L) \sigma>\tau$ for a female-beneficial allele, and $\sigma>2(1-L) \tau$ for a male-beneficial one. Thus, paternal escape relatively promotes the invasion of male-beneficial alleles, and limits the invasion of female-beneficial alleles. In natural populations, levels of paternal escape are probably relatively low (in Planococcocus citri, the proportion of paternal transmission was estimated to be between 0.37 and $3.39 \%$; de la Filia et al. 2019), and thus, very similar to the conventional haplodiploid case. Nonetheless, slight differences in the degree of leakage between populations, such as those documented between ecotypes of Pediculus humanus (de la Filia et al. 2018), or potentially experimentally induced paternal leakage, may allow for effective comparative tests.

\section{ASYMMETRIC PLOIDY AND GENE EFFECTS}

While the different haplodiploid systems are united by their common transmission genetics, they often show distinct somatic genetics (Fig. 1). These differences in the number of gene copies carried by males and females, and the particular expression patterns of those genes, may alter the relative magnitude of allelic effects in males and females (i.e., the marginal costs $\tau$ and benefits $\sigma$ described above), and thus, further shape the dynamics of sexual antagonism.

Under arrhenotoky, females carry two genes at each locus, while males carry only one. This is conceptually similar to the $\mathrm{X}$ chromosomes in an XO system (or an XY system insofar as there is no homologue on the $\mathrm{Y}$ ) and, as with $\mathrm{X}$ chromosomes, it is not necessarily straightforward to compare relative fitness effects across ploidy levels. If an allele's effect is of similar magnitude in a homozygous and a hemizygous setting, then this will mean that alleles will typically have larger effects on average when expressed in males than in females (Charlesworth et al. 1987; Orr and Otto 1994; Hitchcock and Gardner 2020). For example, if we consider the fitness scheme outlined in Table 1, whereby an allele confers a fitness benefit $S$ when in hemizygous or homozygous form, then assuming that the allele is vanishingly rare in the population $(p \rightarrow 0)$ and that allelic effects are additive $\left(h_{f}=1 / 2\right)$, a gene expressing this variant strategy will have a marginal fitness effect of $\sigma=S / 2$ if female-beneficial, but $\sigma=S$ if male-beneficial (Table 1). Alternatively, we might assume that a mutant allele's effect scales with its absolute rather than relative dosage in the genome (Frank 2003; Gardner 2012; Davies and Gardner 2014), in which case, the marginal fitness effects will not systematically differ across the sexes ( $\sigma=S / 2$ for both males and females). While here we follow the typical assumption of hemizygote/homozygote equivalence (Table 1), given mechanisms of apparent dosage compensation in some species-such as compensatory endoreduplication in polyploidy tissues of Hymenoptera (Rasch et al. 1977; Aron et al. 2005; Scholes et al. 2013) and differential methylation of haploid and diploid male ants (Glastad et al. 2014) —in certain tissues and biological processes it may be more accurate to assume that gene effects scale with absolute copy number, or indeed somewhere in between.

In contrast to arrhenotoky, under PGE, both males and females are initially diploid. If both gene copies within the individual are expressed then, for both males and females, the marginal fitness benefit will be $\sigma=S / 2$, as is also the case for eumendelian diploidy (Table 1). However, among PGE systems there is a diversity in the extent of somatic paternal genome expression. This may occur either because the whole or a part of the paternal genome is eliminated early in development (embryonic PGE), such that somatic tissues are actually haploid, or because the paternal genome is silenced, such that certain tissues are functionally haploid (Burt and Trivers 2006; de la Filia et al. 2021). If a locus is exclusively maternally expressed, then marginal fitness effects are identical to those given for arrhenotoky. Thus, depending on species, tissue, and locus, we expect to observe a continuum between these two scenarios (Fig. 2). For simplicity, we henceforth assume that both gene copies are fully expressed under PGE, a scenario that captures autosomal expression in several PGE clades including springtails, parasitic lice, fungus gnat, and gall midge flies (de la Filia et al. 2015; Fig. 1). It also captures the evolution of a subset of genes and tissues in species, such as mealybugs, where paternal genome silencing appears to be incomplete (de la Filia et al. 2021). In contrast, species with embryonic PGE (Fig. 1) are equivalent to arrhenotokous species as males become fully haploid early in development. 
Table 1. Fitness scheme for invasion analysis.

\begin{tabular}{llll}
\hline & & Female benefit/Male cost & Male benefit/Female cost \\
\hline Female genotypes & $F_{00}$ & 1 & 1 \\
& $F_{01} / F_{10}$ & $1+h_{f} S$ & $1-h_{f} T$ \\
& $F_{11}$ & $1+S$ & $1-T$ \\
Male genotypes & $M_{00} / M_{0}$ & 1 & 1 \\
& $M_{01} / M_{10}$ & $1-h_{m} T$ & $1+h_{m} S$ \\
Diploidy/ & $M_{11} / M_{1}$ & $1-T$ & $1+S$ \\
Germline PGE & $\sigma$ & $h_{f} S$ & $h_{m} S$ \\
Arrhenotoky/ & $\tau$ & $h_{m} T$ & $h_{f} T$ \\
Embryonic PGE & $\sigma$ & $h_{f} S$ & $S$ \\
\hline
\end{tabular}

Marginal fitness effects are calculated when the allele is vanishingly rare (i.e., $\lim _{p \rightarrow 0} \sigma(p), \lim _{p \rightarrow 0} \tau(p)$ ) and when there is no population structure.

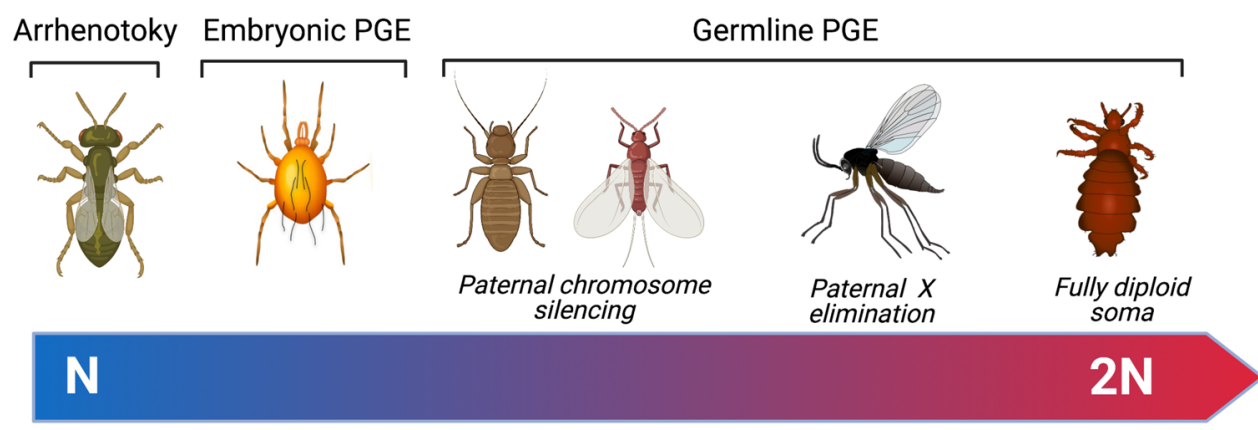

Ploidy male soma

Figure 2. The continuum of male gene expression and, thus, effective ploidy level found across haplodiploid groups with representative taxa illustrated. From left to right, Nasonia vitripennis, predatory mite (Phytoseiulus persimilis), Liposcelis booklice, citrus mealybug male (Planococcus citri), Hessian fly (Mayetiola destructor), and head louse (Pediculus humanus capitis). Figure created with BioRender.com.

A further factor that may modulate the relative scaling of gene effects across sexes is dominance (Rice 1984; Fry 2010; Patten 2019). Dominance coefficients allow for nonadditive scalings of allelic effects between the two homozygous genotypes (Table 1). Relaxing our above assumption about additivity, a female-beneficial allele will confer a marginal fitness benefit of $\sigma=h_{f} S$ under diploidy, PGE, and arrhenotoky (Table 1), while it will confer a marginal fitness cost of $\tau=h_{m} T$ under diploidy and PGE, but $\tau=T$ under arrhenotoky (Table 1). Thus, we can see that for a given $S$ and $T$ the marginal cost to benefit ratio $(\tau: \sigma)$ will be equal under diploidy and PGE, but will be systematically larger under arrhenotoky, with the extent determined by the values of $h_{f}$ and $h_{m}$. The reverse of course will occur when the allele is male-beneficial, with the cost to benefit ratio $(\tau: \sigma)$ is smaller under arrhenotoky than under PGE. Dominance effects may arise for multiple reasons including nonadditive physiology and nonlinear fitness landscapes. Depending on the assumption about the source of dominance, then different assumptions may be made about how dominance in one sex relates to dominance in the other, and similarly how the dominance of beneficial alleles relates to those of deleterious ones, with these assumptions shaping the marginal costs and benefits experienced (Fry 2010; Patten 2019). For simplicity, we restrict our attention largely to the additive case, however, the consequences of two sets of assumptions about the nature of dominance-equal dominance $\left(h_{f}=h_{m}\right)$ and dominance reversals $\left(h_{f}=1-h_{m}\right)$-can be seen in Figure 3, with full results for arbitrary dominance to be found in the supplementary material (SM) $\$ 2.4 .1$.

Integrating the weightings from transmission with the marginal fitness effects, we find that, following the fitness scheme in Table 1 and assuming outbreeding, the condition for a female-beneficial allele to invade from rarity will be $2 h_{f} S>$ $T$ under arrhenotoky and $2 h_{f} S>h_{m} T$ under male PGE. For a male-beneficial allele, the invasion conditions will be $S>2 h_{f} T$ and $h_{m} S>2 h_{f} T$ under arrhenotoky and male PGE, respectively (full methods can be found in SM 2.1-2.2). Note that results for arrhenotoky are identical to the invasion conditions for Xlinked alleles with full dosage compensation (Rice 1984; Patten 2019), and assuming equal dominance $\left(h_{f}=h_{m}\right)$ also recovers the invasion conditions for PGE reported by Klein et al. (2021). 
A

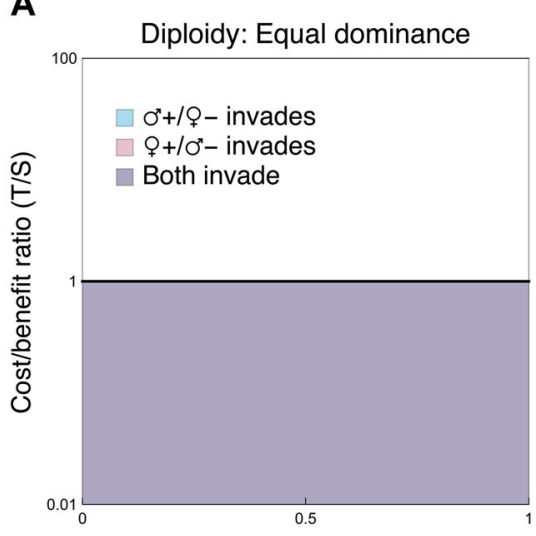

D

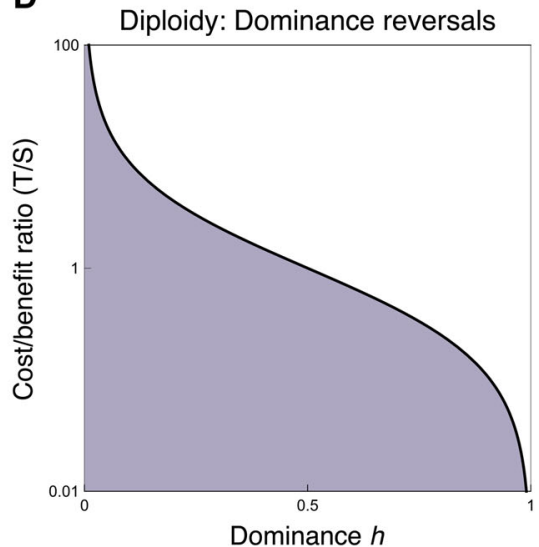

B

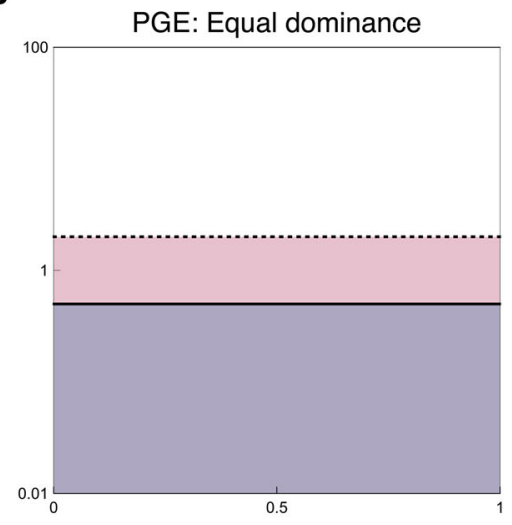

E

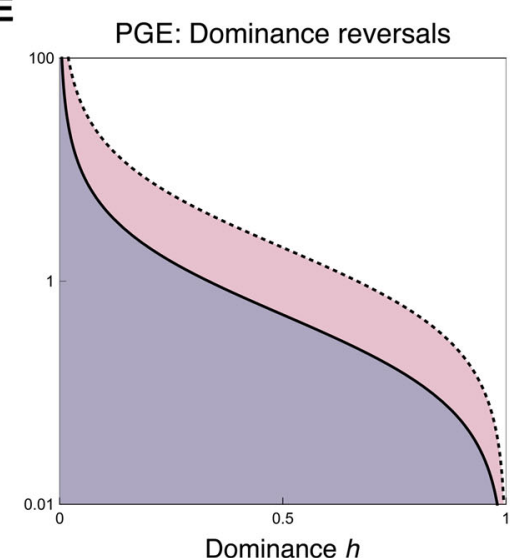

C

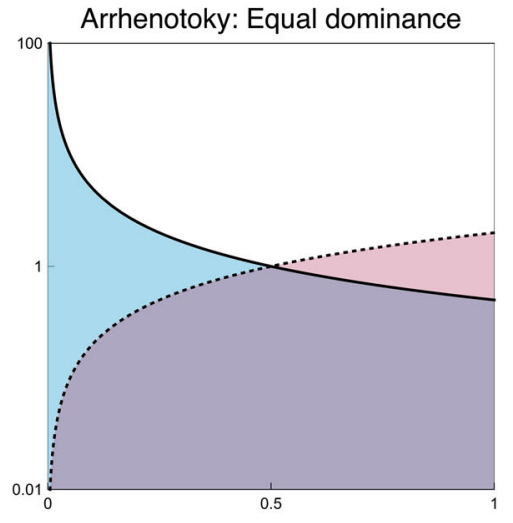

$\mathbf{F}$

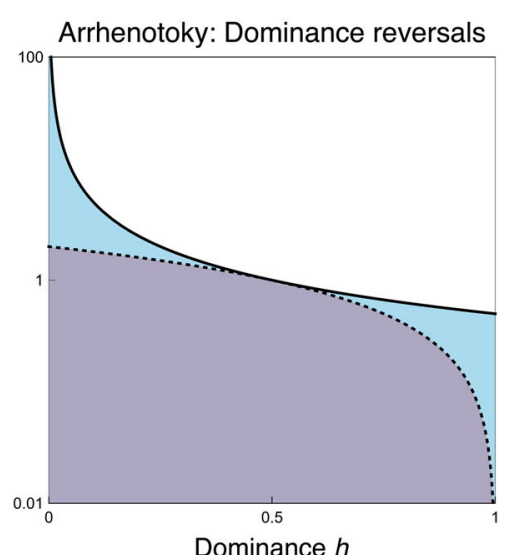

Figure 3. Female-beneficial alleles invade more readily under germline PGE than they do under arrhenotoky. The invasion space for sexually antagonistic mutations with a given genotypic cost/benefit ratio $(T / S)$ under different inheritance schemes and assumptions about dominance $(h)$, with male-beneficial alleles invading beneath the solid line, and female-beneficial alleles beneath the dotted line. In the equal dominance scenarios (a-c): $h=h_{f}=h_{m}$ for both male- and female-beneficial alleles. In the reversals of dominance scenarios (d-f): $h=h_{f}=1-h_{m}$ for the male-beneficial scenario, and $h=1-h_{f}=h_{m}$ for the female-beneficial scenario.

Under arrhenotoky (as with X-linked genes), the twofold weighting placed on females will be cancelled out by the twofold larger fitness effects in males (assuming $h_{f}=1 / 2$ ). In contrast, under male PGE, where marginal fitness effects are not systematically different across sexes, this cancellation does not occur. Thus, we would generally expect relative feminization of the genome in PGE species as compared to arrhenotokous ones, as invasion conditions for female-beneficial alleles are less stringent, and those male-beneficial alleles are more stringent (Fig. 3).

\section{Ecological Asymmetries SIB-MATING AND ECOLOGICAL ASYMMETRIES BETWEEN THE SEXES}

The above results apply to outbreeding populations with no social interactions between relatives, and therefore, it is only the direct fitness effects of alleles that required consideration. But many haplodiploid species diverge from this, with mating schemes and life cycles that result in chronic inbreeding (Hamilton 1967,
1978, 1993). These population structures may alter the relatedness within and between individuals, as well as the intensity with which males and females compete with relatives, potentially generating indirect fitness effects of sexually antagonistic alleles upon social partners. Such factors have long been recognized in sex allocation research to alter the relative value of sons and daughters (Taylor 1981; Frank 1986b; Nagelkerke and Sabelis 1996; West 2009), and thus, may be expected to play a similar role with regards to sexual antagonism.

We investigate how inbreeding may modulate sexual antagonism by modeling a population of monogamous females, in which a proportion $s$ of females in the brood mate with their sibs, while a proportion $1-s$ mate with males from the population at large (Fig. 4). Introducing sib-mating has multiple distinct effects upon sexual antagonism. The first is that sib-mating inflates the consanguinity of an individual to themselves, that is, their inbredness (sensu Frank 1986a), which has a feminization promoting effect under arrhenotoky — as a gene copy will have indirect fitness effects upon the other identical by descent gene copy 


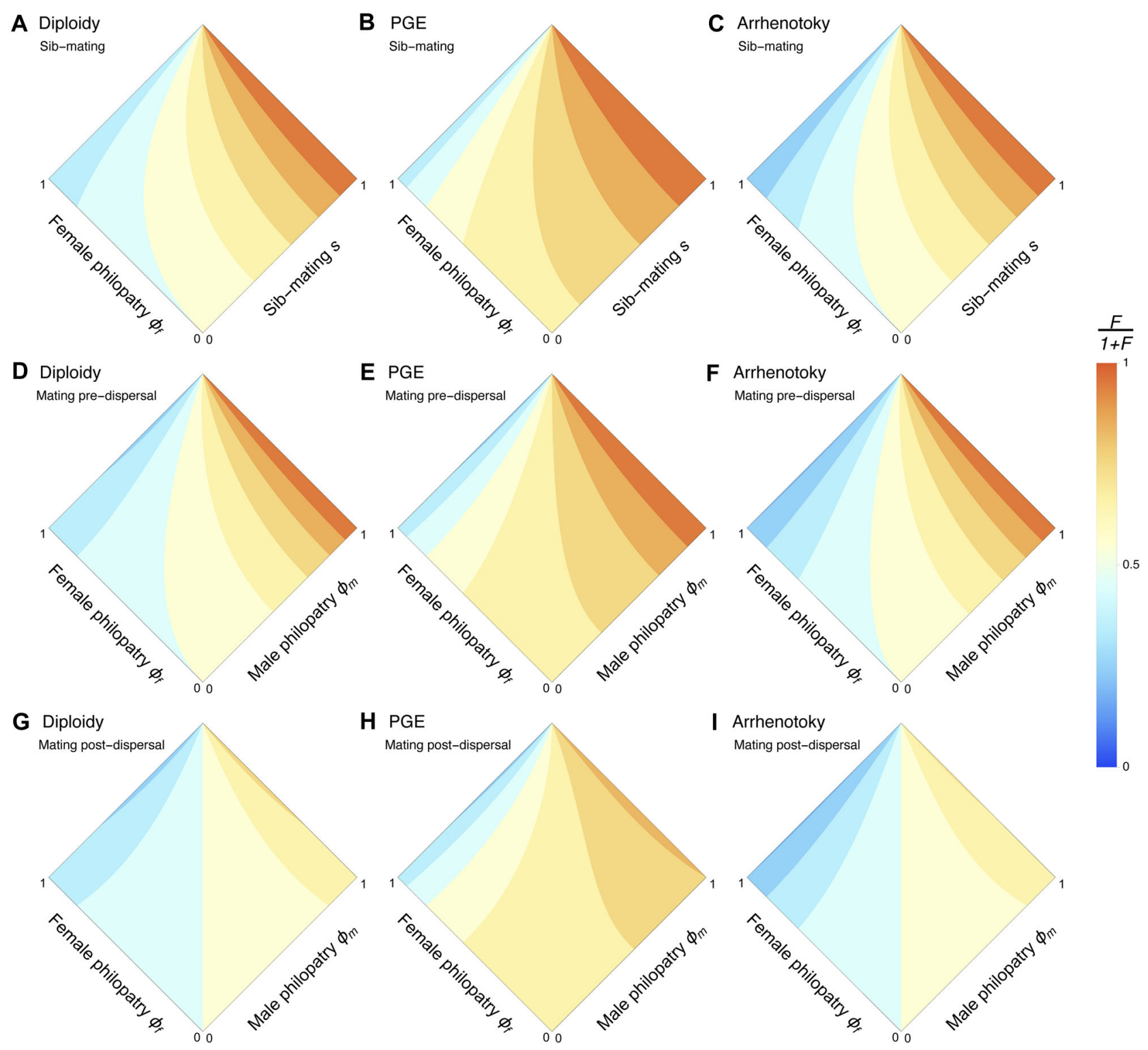

Figure 4. Mating ecology and dispersal modulate the degree of feminization. Here, the degree of feminization, $F /(1+F)$, is plotted as a function of either the amount of male and female philopatry, or the amount of female philopatry and the proportion of sib-mating, under three inheritance systems (diploidy, germline PGE, and arrhenotoky), and for three mating ecologies (sib-mating [A-C], viscous population with mating prefemale dispersal [D-F], and viscous population with mating postfemale dispersal $[G-I])$.When $F /(1+F)>0.5$, then feminization is expected, and when $F /(1+F)<0.5$ masculinsation is expected.

in females, but not in males, which are haploid (Tazzyman and Abbott 2015; Hitchcock and Gardner 2020)_but not for PGE or diploidy, where gene copies in both males and females experience these within individual indirect fitness effects. Second, sib-mating increases the probability that males will compete with brothers for mates, discounting the inclusive-fitness benefits of male-beneficial alleles to their male carriers, and mollifying the inclusive-fitness costs of male-deleterious alleles. Third, the direct fitness effects of alleles upon their female carriers will have indirect fitness effects upon their carriers' mates. If females sibmate, then female-beneficial alleles will generate indirect bene- fits for their brothers, and female-deleterious alleles will impose indirect costs. All three of these effects have parallels in sex allocation, with increased sib-mating increasing the relatedness of a female to her daughters but not her sons under arrhenotoky, increased competition between brothers decreasing the genetic returns on males (i.e., local mate competition; Hamilton 1967), and increased sib-mating meaning that increased investment into daughters will increase the fitness of sons, either through extra mating opportunities, or through higher quality mates (Taylor 1981; Frank 1986b; West 2009;). While here we focus on the additive case, it is worth noting that sib-mating (and inbreeding 
more generally) will also negate the effects of dominance by inflating the proportion of individuals who are homozygous (with concomitant effects on the maintenance of polymorphisms) (Jordan and Connallon 2014; Flintham et al. 2021; SM §2.5).

Collecting these effects, we write out the condition for a female-beneficial allele to invade. We then rearrange that condition into the form $F>T / S$, where $F$ describes the "potential for feminization" (cf. Gardner 2010). This term bundles together the various weightings that are placed upon $T$ and $S$, whether they emerge from aspects of the ecology or genetic system, providing a threshold that the cost-to-benefit ratio must not exceed in order for a female-beneficial allele to invade, and thus, $F$ describes the stringency of those invasion conditions. For example, the result discussed above for arrhenotokous organisms, $2 h_{f} S>T$ (Rice 1984), rearranges to give $F=2 h_{f}$. When $F=1$, then the cost $T$ simply has to be less than the benefit $S$ for the allele to invade-as in the additive eumendelian diploid case. But as $F$ increases, then the condition $F>T / S$ becomes easier to satisfy, and alleles which confer greater costs than benefits (i.e., $T / S>1$ ) may yet be able to invade. Conversely, as $F$ decreases, then the condition $F>T / S$ becomes harder to satisfy, and alleles which confer greater benefits than costs (i.e., $T / S<1$ ) may be unable to invade. A similar approach may be taken to write out a potential for masculinzation (i.e., a male-beneficial allele invades when $M>T / S$ ) and, so long as the alleles under comparison do not differ with respect to dominance between the two scenarios, this is the reciprocal of the potential for feminization $(F=1 / M)$. Thus, as conditions becomes less stringent for female-beneficial alleles to invade, they necessarily become more stringent for male-beneficial alleles. Therefore, when $F>1$ feminisation is expected, and when $F<1$ masculination is expected. Note that this potential for feminisation is distinct from other uses of feminisation in work on sex ratio distorters (e.g. Hatcher and Dunn 1995). Assuming additivity and weak selection, we find that under arrhenotoky and diploidy $F=1 /(1-s)$, and under male PGE $F=(4-\mathrm{s}) /(2(1-\mathrm{s}))$. Thus, we find that, across all these genetic systems, increased sib-mating promotes feminisation, with the effect being strongest under PGE (see Fig. 4). Results for nonadditive scenarios and stronger selection regimes can be found in SM $\$ \S 2.3-2.5$, with full methodology outlined in SM $\S 1.1$ and SM $\S \S 2.1-2.2$.

So far, we have assumed that females compete globally, however, many haplodiploid species have more generally viscous populations in which females may also disperse short distancesif at all. For instance, in the date stone beetle, females may start their own families within the seed in which they were born (Spennemann 2019). Similarly, in many mealybugs, females crawl relatively small distances away from their natal patch (Varndell and Godfray 1996; Ross et al. 2010a). In these species, females may compete with sisters for breeding spots, just as their broth- ers competed with each other for mates, that is, local resource competition (Clark 1978). Incorporating these factors yields two further consequences for sexual antagonism. First, with limited female dispersal, direct fitness benefits to females incur indirect fitness costs to their sisters by depriving them of breeding spots, just as obtained for local mate competition in males. Second, while a fit female confers indirect fitness benefits upon brothers with whom she mates, she may also incur indirect fitness costs by competing with her brothers' mates, and thereby, indirectly depriving her brothers of reproductive success. With increasing local resource competition, the invasion condition becomes less stringent for male-beneficial alleles and more stringent for female-beneficial alleles. The dual effects of sib-mating and limited female dispersal can be seen in Figure 4, with full analytical results in SM §2.4.1.

\section{ALTERNATIVE LIFE-CYCLES AND MODES OF INBREEDING}

Above, we considered one particular inbreeding scenario, in which a fixed proportion of matings is reserved for siblings. However, the specific mechanism by which inbreeding occurs may also modulate sexual antagonism, as different mating schemes and life cycles will differ in how relatedness builds up, and how intensely males and females compete with relatives. To investigate this, we contrast the above model with an alternative involving a patch structured population in which the degree of inbreeding is modulated by the extent of dispersal (Wright 1931), whereby males remain on their natal patch with probability $\phi_{m}$, and females with probability $\phi_{f}$. We consider two variants, the first in which mating occurs before female dispersal (male dispersal $\rightarrow$ mating $\rightarrow$ female dispersal, DMD), and a second in which mating occurs after female dispersal (male dispersal $\rightarrow$ female dispersal $\rightarrow$ mating, DDM), the latter of which has been recently investigated by Flintham et al. (2021) for sexual antagonism in relation to diploidy and $\mathrm{X}$-linkage. Comparing these results, we obtain a ranking of highest potential for feminization under sibmating, followed by DMD, and finally DDM (Fig. 4, see SM $\S 1.1$ for life-cycle details, SM §§2.1-2.2 for Methods, and SM $\$ 2.4 .1$ for Results). The sib-mating and DMD scenarios are very similar, except that brothers are more likely to compete for mating opportunities in the former scenario, promoting feminization, analogous to the difference between fixed self-fertilization and mass-action selfing models of hermaphroditic plants (Jordan and Connallon 2014). Compared to DDM, both sib-mating and DMD scenarios yield a higher potential for feminization, as they involve both higher rates of consanguineous mating and also sisters conferring fitness benefits upon related mating partners, an effect that is exactly cancelled under DDM by increased competition between females and their brothers' mates. Thus, different 
mating ecologies and life-cycle structures yield different patterns of feminization.

Alongside the generic demographies discussed above, haplodiploids present a striking variety of unusual lifecycles and modes of inbreeding. For illustration, we consider two scenarios in detail, both of which involve females effectively engaging in "selfing". First, oedipal mating (Fig. 1) occurs because a virgin female may produce an exclusively male brood with which she then mates, a reproductive strategy observed in groups including mites (McCulloch and Owen 2012; Tuan et al. 2016), beetles (Entwistle 1964; Jordal et al. 2001), parasitoid wasps (Browne 1922; Schneider et al. 2002), pinworms (Adamson and Ludwig 1993), and thrips (Ding et al. 2018). Second, in the scale insect I. purchasi, selfing is understood to occur as a consequence of a diploid female containing a transovarially transmitted haploid spermatogenic cell lineage that may fertilize her eggs (Royer 1975; Normark 2009; Ross et al. 2010b; Mongue et al. 2021). While these two systems are very different in their biological details, in both cases, we find that higher rates of "selfing" increases the potential for feminization, and do so in a fashion that is qualitatively very similar to sib-mating (see SM $\S \S 1.1,2.1-2.2$ for Methods, and SM \$2.4.3 for Results).

\section{Conflicts Over Sexual Antagonism PARENT-OFFSPRING CONFLICT OVER SEXUALLY ANTAGONISTIC TRAITS}

In the foregoing, we have assumed that the sexually antagonistic traits of interest are under the sole control of the individuals in which they are expressed. However, an individual's traits may also be influenced by social partners. In particular, parents may play an important role in shaping the traits of their offspring, whether it be through the material constitution of the zygote, the environment in which those offspring develop, or through the care that those parents provide (Mousseau and Dingle 1991; Mousseau and Fox 1998; Crean and Bonduriansky 2014; Bebbington and Groothuis 2021). For example, in the spider mite (Tetranychus urticae), maternal environment is known to affect offspring traits including juvenile survival (Marinosci et al. 2015), dispersal behavior (Bitume et al. 2014), and diapause induction (Oku et al. 2003). If the traits that they influence are sexually antagonistic, then parents may face a trade-off between crafting superior daughters versus superior sons. Moreover, if parents place different values upon males and females as compared to their offspring, then this may lead to parent-offspring conflict (sensu Trivers 1974) with respect to sexually antagonistic traits. Furthermore, if mothers and fathers also differ in their relative valuations of sons and daughters then this may lead to sexual conflict (sensu Trivers 1972) with respect to sexually antagonistic traits.
Focusing our attention first on genes acting through mothers, if we consider the invasion of an allele which increases the fitness of her daughters, but decreases the fitness of her sons, then for diploidy the potential for feminization may be expressed as $F=(1+s) /(1-s)$. When there is no sib-mating ( $s=0$ ), then this is equivalent to that for offspring, a result previously found when considering organisms with a dominant haploid phase (Patten and Haig 2009). However, under sibmating the interests of mothers and offspring diverge, with mothers favoring a greater female bias than their offspring (Fig. 5A). This parallels a previous effect found in relation to sex allocation, whereby offspring typically favor less extreme sex ratio deviations than their parents (Trivers 1974; Werren and Hatcher 2000; Pen 2006), on account of parents being favored to maximize the success of the entire brood whereas each individual values itself more than its siblings (although see Pen (2006) for situations where this pattern may be reversed). For arrhenotoky and PGE, $F=\left[3-(1-s)^{2}\right] /[(1-s)(2-s)]$. Thus, for arrhenotoky, the situation is similar to diploidy, with mothers and offspring in agreement under random mating, but with mothers favouring a greater female bias when there is sib-mating (Fig. 5C). For PGE, however, when there is no sib-mating then offspring favor more female bias than their mothers, as females are twice as valuable as males from the perspective of the offspring, while sons and daughters are equally valuable from their mothers' perspective. However, this situation reverses as sibmating increases, with mothers once again favoring more femalebiased trait values than their offsprings (Fig. 5B).

Considering instead a sexually antagonistic allele that acts through fathers, we find that for diploidy the potential for feminization is the same as for mothers, $F=(1+s) /(1-s)$, and with both parents favoring a more female-biased trait value than offspring. For arrhenotoky, however, fathers favor a far more feminized trait value than either offspring or mothers, $F=\left[3+(1-s)^{2}\right] /[(1-s) s]$, as they only contribute genetically to their daughters in the brood. This is similar to how, under outbreeding, arrhenotokous fathers (and X chromosomes in males) favor exclusively female broods (Hamilton 1967), or investment solely into daughters (Rice et al. 2008; Friberg and Rice 2014; see also Miller et al. 2006). Nonetheless, with increased sib-mating they are increasingly related to their mates' sons, and thus place value on their fitness too, but with further sib-mating this is counteracted by the effects of increased local mate competition, once again favoring feminization (Fig. 5C). PGE yields a qualitatively similar outcome; however, as a male's paternal-origin genome is passed to neither sons nor daughters directly, then fathers are not as highly related to their daughters as compared with arrhenotoky, and they therefore, favor slightly less feminization (Fig. 5B), with the potential for feminization $\quad F=[6-(1-s)(2-s)(1+s)] /[(1-s)(3-s) s]$. 
A

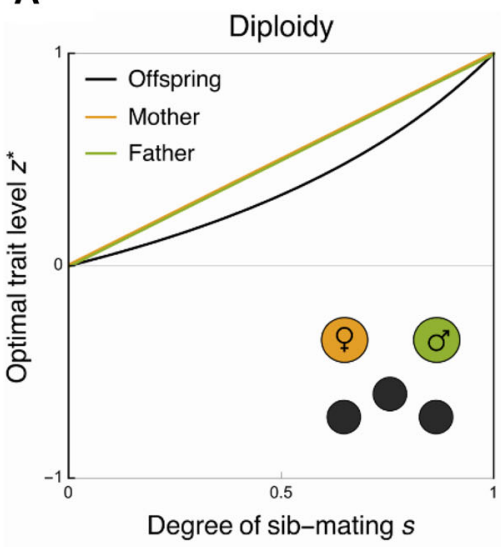

D

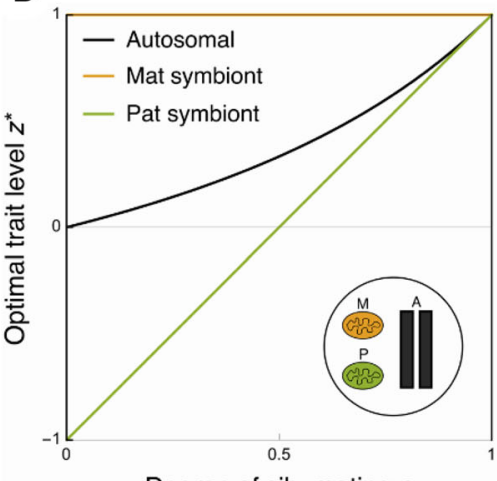

Degree of sib-mating $s$

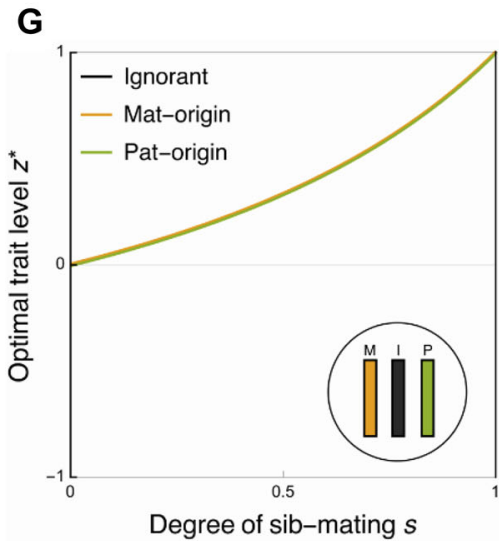

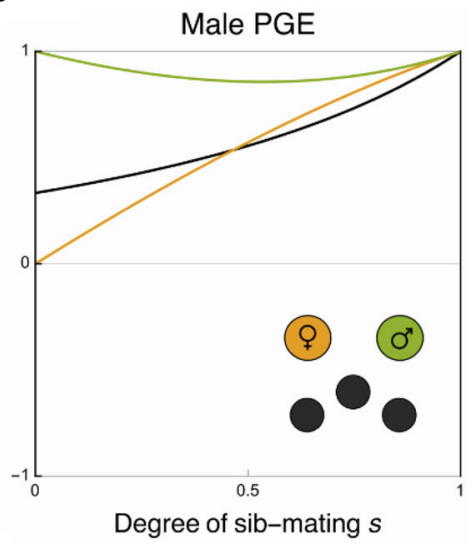

E

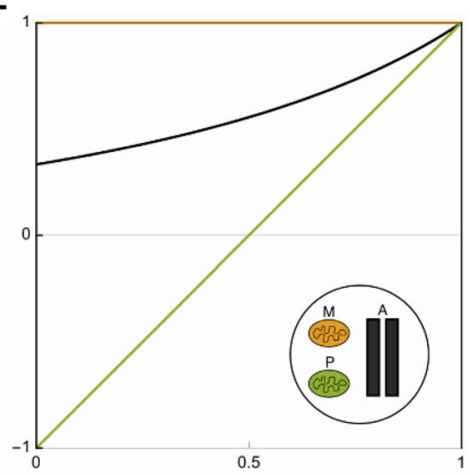

Degree of sib-mating $s$

H

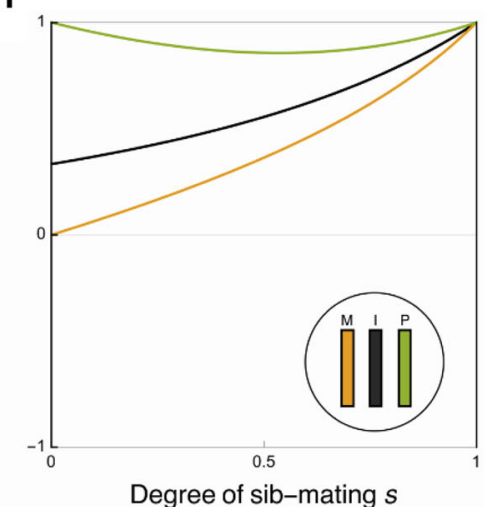

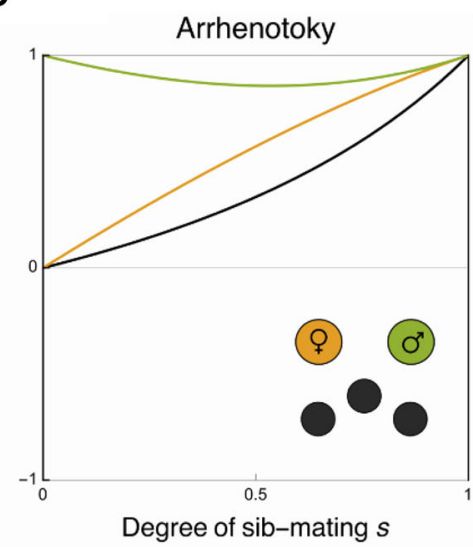

$\mathbf{F}$

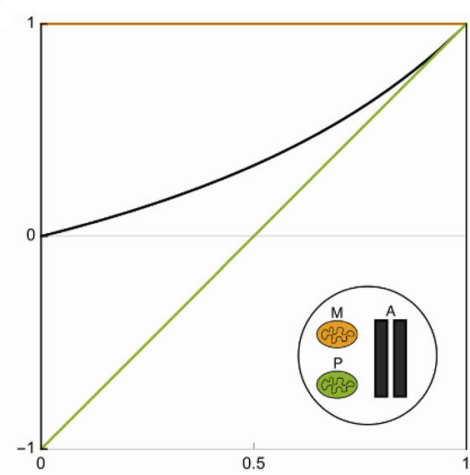

Degree of sib-mating $s$

I

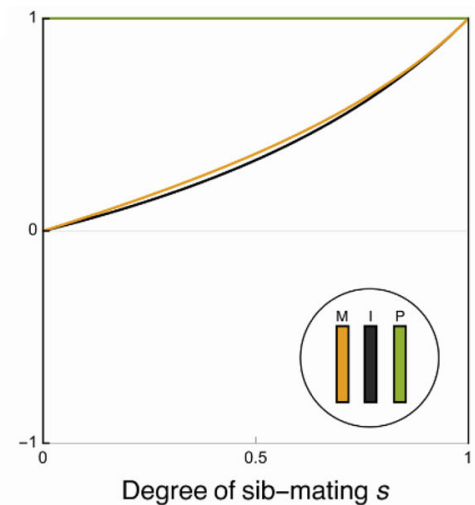

Figure 5. Conflicts within and between individuals over sexually antagonistic traits, across different genetic systems. The optimal level of a sexually antagonistic trait $z$ under diploidy, germline PGE, and arrhenotoky when control of that trait is assigned to: offspring, mothers, and fathers (A-C); autosomal genes, matrilineal cytoplasmic genes, and patrilineal cytoplasmic genes (D-F); ignorant genes, maternal-origin genes, and paternal-origin genes (G-I). In these examples, fitness is a Gaussian distributed trait with an optimum of 1 for females and -1 for males, with equal variance. Full details of methodology can be seen in §§SM 3.1-3.8.

Full results for nonadditive scenarios can be found in SM $\$ 2.4 .1$.

\section{ENDOSYMBIONTS, MITOCHONDRIA, AND GERMLINE RESTRICTED CHROMOSOMES}

Thus far, we have largely treated the genome as though it is a unified entity. However, even though different genes may re- side within the same body, they may nevertheless have distinct inclusive-fitness interests (Hamilton 1967; Burt and Trivers 2006; Gardner and Úbeda 2017), and thus, come into conflict over the trade-offs imposed by sexual antagonism. This is particularly relevant for haplodiploids as many contain endosymbionts which have different transmission modes to autosomal genes (Buchner 1965; Normark 2004a; Ross et al. 2012; Perlmutter and 
Bordenstein 2020), and thus, may place different valuations upon males and females (Hurst 1991; Frank and Hurst 1996). Similarly, particular species also contain further unusual genomic features, such as the matrilineally inherited germline restricted $\mathrm{E}$ chromosomes found in gall midges (Harris et al. 2003; Normark 2004a; Hodson and Ross 2021).

For those endosymbionts and chromosomes that are strictly matrilineally inherited, they will place no direct value upon the fitness of males, bringing them into conflict with the rest of the genome (Wade 2014; Hurst and Frost 2015). These elements may also, therefore, provide a rich source of evidence for the "Mother's Curse" hypothesis, that is, that mitochondria accumulate mutations which are deleterious for males (Gemmell et al. 2004). Under full outbreeding, this conflict is at its most intense, but with increasing amounts of sib-mating the autosomes become increasingly female-biased too, aligning the interests of these two sets of genes, and thus reducing the extent of the conflict. This also applies to patrilineally inherited symbionts, which although much rarer than matrilineally inherited counterparts have been documented in a variety of species including aphids (Moran and Dunbar 2006), mosquitos (Damiani et al. 2008), leafhoppers (Watanabe et al. 2014), termites (Korb and Aanen 2003), and tsetse flies (De Vooght et al. 2015). With full outbreeding, paternally inherited genes place no value on females, but as inbreeding increases then they place an increasing value on the fitness of females, mollifying the conflict between them, autosomal, and maternal-inherited genes, as shown in Figure 5D-F.

\section{PARENT-OF-ORIGIN SPECIFIC GENE EXPRESSION}

Finally, a further intragenomic conflict that may emerge over sexual antagonism is between maternal- and paternal-origin genes (Haig 2002). The asymmetric transmission genetics that defines haplodiploidy may subsequently generate differences between maternal- and paternal-origin genes in how they value males and females, and also their relatedness to the males and females with whom they interact (Haig 1992; Queller and Strassmann 2002; Queller 2003; Wild and West 2009; Rautiala and Gardner 2016; Marshall et al. 2020).

In the simplest case, with full outbreeding, we find that if a gene is of maternal-origin it places equal value upon males and females, under diploidy, arrhenotoky, and PGE. Conversely, if it is of paternal-origin then it places equal value upon males and females under diploidy, but places no value upon males under the haplodiploid systems, as it is never transmitted by males under PGE, and is absent from males under arrhenotoky. Focusing on PGE, we can explore how, depending on which gene copy controls the trait, the potential for feminization may change. This is particularly relevant as the extent of expression in males from the maternal- and paternal-origin copies may vary across loci, tissues, and species (Burt and Trivers 2006; Gardner and Ross 2014; de la Filia et al. 2021). Allowing for a proportion $y$ of a locus's expression in a male to come from the paternal-origin copy, and a proportion $1-y$ to come from the maternal-origin copy, we find that the potential for feminisation is $F=1 /(1-y)$. Thus, when maternal-origin genes control the trait in males $(y=0)$, then $F=1$, equivalent to the arrhenotokous case, whie when expression is exclusively from the paternal-origin copy $(y=1)$, then $F=\infty$, that is, female-beneficial alleles will always invade, regardless of the cost they impose upon males, analogous to how paternal-origin genes may favor male suicide when there is competition between male and female siblings (Ross et al. 2011b).

As the rate of sib-mating increases, the intragenomic conflicts become more complex. We now explore the effects of parent-of-origin specific gene expression in both males and females. Allow for a proportion $y$ of a locus's expression in males to come from their paternal-origin copy and a proportion $1-y$ from their maternal-origin copy, and allowing a proportion $x$ of that locus's gene expression in females to come from their maternalorigin copy, and proportion $1-x$ from their paternal-origin copy. Then, we find the degree of feminisation under PGE becomes:

$$
F=\frac{4-s(2-s-2(1-s) x)}{(1-s)(4-s-2(2-s) y)} .
$$

With the results for arrhenotoky generated by setting $y=0$. We can see that assigning full control to maternal-origin copy in both sexes $(x=1, y=0)$, conditions simplify to $F=$ $[(2+s)(2-s)] /[(4-s)(1-s)]$, which is a monotonically increasing function of $s$, that is, the degree of feminization always increases as the rate of sib-mating increases. In contrast, if we assign full control to the paternal-origin genes $(x=0, y=1)$, then $F=\left[3+(1-s)^{2}\right] /[(1-s) s]$. In the absence of sib-mating $(s=0)$, then the paternal-origin copy is unrelated to the other gene copy in a male, and thus, places no value on male fitness. As the rate of sib-mating increases then the value that a paternalorigin gene places on males increases too, as that gene copy is related to the other gene copy it resides in a male with. However, with further increases in the rate of sib-mating, this is countered both by the increasing competition between related males, and also the indirect effects from related females.

Previously, intragenomic conflict between maternal- and paternal-origin genes has been suggested to drive the evolution of genomic imprinting at such loci, that is, the expression of one parental copy and the silencing of the other parental copy. This results from an escalating conflict over joint expression levels, which ultimately results in the gene copy that favors lower expression levels becoming silenced, while the one that favors higher expression levels is expressed at its optimum level, a process termed the "loudest voice prevails" principle (Haig 1996). If we apply the logic of this principle to conflict over sexually antagonistic traits then, under PGE, we may expect paternal-origin 


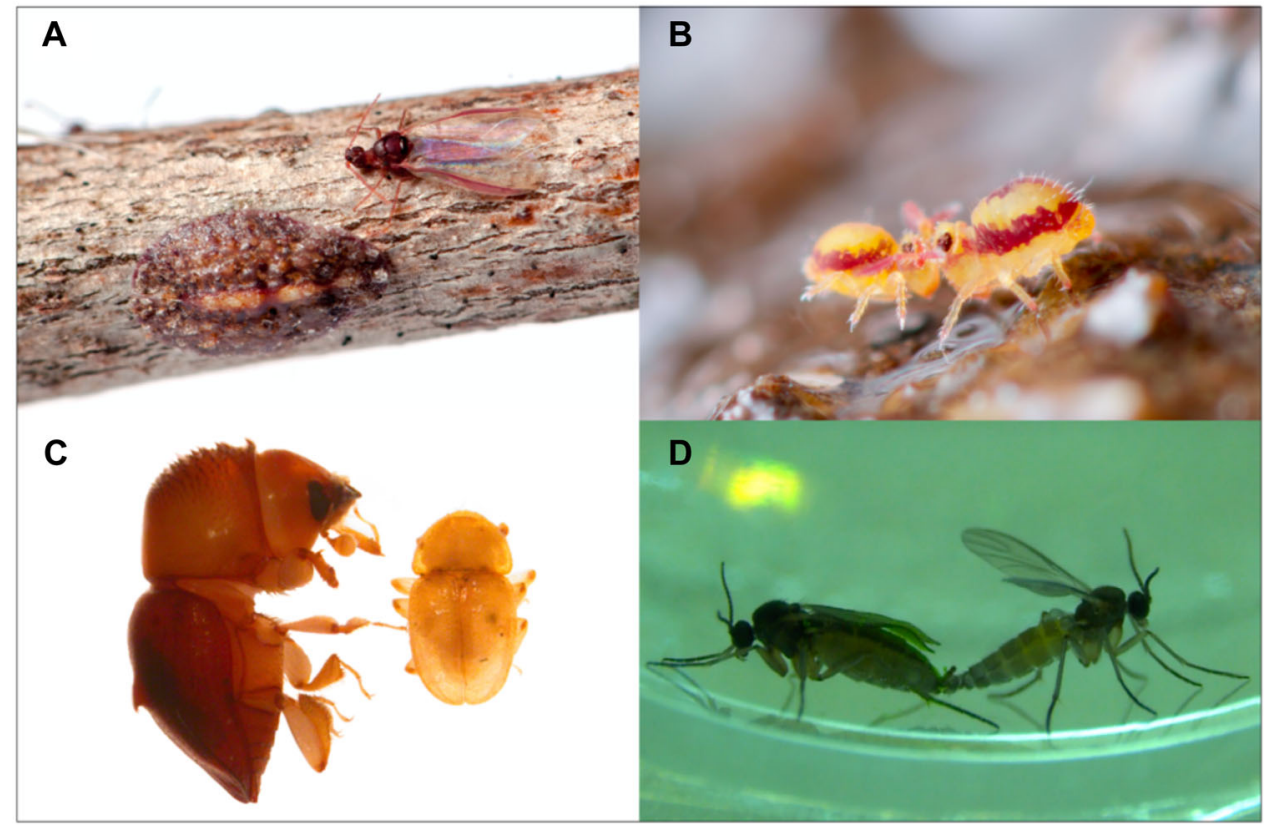

Figure 6. Examples of sexual dimorphism in haplodiploid species. (A) Soft scale insects (Pulvinaria acericola), female on the left, male on the right (credit: Matt Bertone). (B) Globular springtail (Sminthurides malmgreni), male on the left, female on the right (credit: Andy Murray, chaosofdelight.org). (C) Ambrosia beetle (Diuncus sp.) female on the left, male on the right (credit: Jiri Hulcr). (D) Fungus gnats (Bradysia coprophila), female left, male right (credit: Robert Baird).

genes to be expressed for female-beneficial trait promoters and male-beneficial trait inhibitors, while we would expect maternalorigin genes to be expressed for male-beneficial trait promoters, and female-beneficial trait inhibitors. Note that this is distinct from other theories about how sexual antagonism may give rise to genomic imprinting (Iwasa and Pomiankowski 1999, 2001; Day and Bonduriansky 2004), with predictions about the expected direction of imprint likely to differ also.

\section{Discussion}

Haplodiploid species account for a large minority of all animal species (Normark 2003, 2006; Bachtrog et al. 2014; de la Filia et al. 2015), with many striking examples of sexual dimorphism (see Fig. 1, 6). Our analyses here have shown how some of the unusual genetic and ecological asymmetries that define these groups are expected to modulate the outcome of sexual antagonism. We find that: (1) PGE promotes female-beneficial alleles more than arrhenotoky (recovering the result given recently by Klein et al. 2021); (2) the extent of this female bias is determined by the amount of paternal leakage and degree of silencing of the paternal genome; (3) the chronic sib-mating associated with many haplodiploid groups promotes feminization, with different modes of inbreeding - including limited male-dispersal, oedipal-mating, and the pseudo-hermaphroditism of $I$. purchasi-having qualitatively similar, but quantitatively different effects; (4) resource competition between related females relatively inhibits femalebeneficial alleles; (5) inbreeding and asymmetric transmission may foment conflicts of interest between different parties over sexually antagonistic traits, including parents and offspring, endosymbionts and their hosts, and maternal- and paternal-origin genes; and (6) such intragenomic conflict provides a novel explanation for the evolution of genomic imprinting.

While our analysis indicates that these groups may provide a particularly rich set of comparative tests for how ecology and genetics modulate sexual antagonism, relatively little work has been carried out to investigate this. One of the reasons for this paucity of research attention is that the within-genome comparisons often used to study sexual antagonism have been considered impossible for the many haplodiploid species that lack sex chromosomes. However, this overlooks the exceptions that provide excellent opportunities for testing theory. For instance, sciarid flies not only have male PGE, but also an XO sex chromosome system (Metz 1938; Rieffel and Crouse 1966), allowing a within-organism comparison of these inheritance systems in relation to sexual antagonism. This is also true of some other groups with germline PGE such as gall midges and globular springtails (Gallun and Hatchett 1969; White 1977; Dallai 2000; Anderson et al. 2020). In these groups, we may expect female-beneficial variants to be enriched on the autosomes, while male-beneficial variants would be expected to be overrepresented on the sex chromosomes, regardless of assumptions about dominance, 
making this a more straightforward prediction than between autosomes and sex chromosomes in conventional eumendelian systems (Rice 1984; Patten 2019). This is similar to how the unusual life cycle and X-chromosome transmission of pea aphids has provided an exceptional test of evolutionary theory in this area by having predictions qualitatively unaffected by dominance (Jaquiéry et al. 2013; Jaquiéry et al. 2021). In addition to X/autosome comparisons, some of these groups contain further genomic elements, such as germline-restricted chromosomes, that are maternally inherited in gall midges and show likely paternally biased inheritance in sciarid flies (Hodson and Ross 2021; Hodson et al. 2021), enabling further within-genome comparisons.

Similarly, while it has been suggested that the X chromosome should be relatively enriched for sexually antagonistic polymorphisms in eumendelian systems as compared to the autosomes (Rice 1984), again this depends on assumptions about dominance (Fry 2010; Ruzicka and Connallon 2020). We find here that the same is true of comparisons between PGE and $\mathrm{X}$ chromosomes or arrhenotoky, with arrhenotokous organisms ones having a higher potential for polymorphism under parallel dominance, but a smaller space for polymorphisms under dominance reversals (see SM \$2.5). Additionally, such sexually antagonistic polymorphisms may be easier to detect in some haplodiploid species as compared to eumendelian ones, because the asymmetric transmission genetics means that allele frequency differences that build up between the sexes in one generation, will carry over to the next (Crow and Kimura 1970; Ruzicka and Connallon 2020).

Additionally, we find that the chronic inbreeding exhibited by many haplodiploids typically promotes feminization. This meshes with the increasing interest in the role of demography and ecology in modulating sexual antagonism (Albert and Otto 2005; Arnqvist 2011; Harts et al. 2014; Tazzyman and Abbott 2015; Connallon et al. 2019; de Vries and Caswell 2019; Hitchcock and Gardner 2020). In particular, Flintham et al. (2021) have recently shown how, in viscous populations, sex-biased dispersal may skew sexual antagonism under diploidy and X-linkage toward the sex that competes less intensely with relatives. Here, we recover that same pattern, but also find that other mating schemes that characterize haplodiploid groups can involve an additional feminizing effect, as females may confer fitness benefits upon their mates. Alongside comparisons between populations and species, one method of testing such predictions would be through the use of experimental evolution. For example, Rodrigues et al. (2021) evolved populations of the spider mite Tetranychus urticae under various dispersal regimes in order to investigate the evolution of sex allocation; those demographies predicted to lead to greater female bias in the sex ratio would also be expected to promote female bias in relation to sexual antagonism. Thus, under these conditions, we may expect to see either increased fixation of female-beneficial sexually antagonistic alleles and/or phenotypes moving toward the female optimum. Reinvestigation of these evolved lines or new experiments with similar design would enable testing of predictions emerging from our analysis.

Furthermore, we have shown how population structure and transmission asymmetries may foment conflicts between different genetic parties over sexually antagonistic traits. In particular, we identify potential for conflict between parents and offspring. While there has been similar work considering the differing interests between parents and offspring with regards to sex allocation (Trivers 1974; Werren and Hatcher 2000; Pen 2006), sexual antagonism provides a further arena for such conflicts of interest. While parent-offspring conflict emerges across all of our genetic systems under sib-mating, species with PGE provide a particularly interesting set of systems within which to investigate this phenomenon as, even under full outbreeding, mothers, fathers, and offspring all favor different trade-offs. Thus, depending on who controls the trait, we may expect different patterns of masculinization versus feminization. Comparisons between spermderived versus egg-derived products, and between those to genes expressed after the maternal-to-zygotic transition, may help reveal such conflicts over development. A further, particularly interesting case to investigate the logic of such conflicts is with the bacteriome of the armored scale insects. These are pentaploid tissues containing two complete copies of the mother's genome and a copy of the paternal-origin genome (Normark 2004b). Thus, while not identical to the parents interests, the bacteriome nonetheless might be expected to have more similar genetic interests to the mother than the offspring it resides within, and thus, the interface between them provides a within-individual arena for this parent-offspring conflict.

We have focused here on cases where there are only two classes of individual: males and females. However, many of the better known haplodiploid species-most notably the eusocial Hymentoptera-exhibit not just sex structure, but also caste structure. For instance, in the eusocial bees, wasps, and ants, in addition to reproductive females (queens) and reproductive males (drones), there is also an additional female neuter class (workers) who are morphologically, physiologically, and behaviorally distinct from the queen. While the addition of caste structure on its own is not expected to modulate sexual antagonism per se, that is, trade-offs between queens and reproductive males, if the trade-off occurs through female workers and reproductive males then results would be expected to diverge, as phenotypic effects that manifest in females would only have indirect effects through their effects on the reproductive females. Moreover, with more than two castes there is the possibility for more complex tradeoffs operating across multiple classes, such as between workers and queens, workers and males, and three-way trade-offs; such 
trade-offs have previously been referred to in terms of "intralocus caste antagonism" (Holman 2014; Pennell et al. 2018). A similar complexity occurs when males exhibit polyphenisms, for instance, in fig wasps between winged and nonwinged male forms (Hamilton 1979; Cook et al. 1997). Such male dimorphism can be extreme, not only concerning the presence/absence of wings, but also with respect to other aspects of morphology and behavior. If a sexually antagonistic allele affects these morphs differently, then outcomes will be more complex than those emerging from our analysis, depending on the relative fraction of male dispersers. Similarly to caste structure, this may lead to trade-offs among these male morphs, previously termed "intralocus tactical evolution" (Morris et al. 2013).

Our predictions have been derived under the assumption of nonoverlapping generations, yet age-structure may also have an important modulating effect on sexual antagonism (de Vries and Caswell 2019; Hitchcock and Gardner 2020). This may be important for two reasons. First, sex-specific age-structure may disturb the reproductive values of males and females away from the ratios given here (Grafen 2014; Hitchcock and Gardner 2020). This may be because there are sex-differences in mortality and fecundity, such as in the citrus mealybug ( $P$. citri) where males live up to only 3 days post eclosion while females can live several weeks (Nelson-Rees 1960; Ross et al. 2011a), or because of other factors which can generate more cryptic age structure such as partial bivoltinism (Seger 1983; Grafen 1986), sperm storage, or worker reproduction (Benford 1978; Charnov 1978; Alpedrinha et al. 2013). Second, population viscosity may generate competition between parents and offspring (Irwin and Taylor 2001; Ronce and Promislow 2010). Coupled with other aspects of sex-biased demography, such as sex-biased dispersal (Johnstone and Cant 2008, 2010), then this may reduce the magnitude of costs or benefits to one sex more than the other, and thus, bias the outcome of sexual antagonism toward one sex. An example relevant to this is the aforementioned date-stone beetle where a single female may spawn up to five generations within a single drupe over the spring and summer (Spennemann 2019), thus generating potentially strong inter- and intragenerational kin competition.

Finally, we have considered mating to be the only social interaction between males and females. Yet invasion conditions for sexually antagonistic alleles are liable to be modulated by more extensive and complex intersexual interactions. For instance, intrabrood competition may result in male-beneficial alleles decreasing the fitness of females both through the direct effect of those alleles being expressed by females, but also through those females being outcompeted by their brothers (and vice versa, for female-beneficial alleles). The extent of such competition will vary with ecological context. For instance, bark beetles are understood to experience intense sib-competition, while phloem feeders are less likely to do so (Normark 2004a, 2006). Intense intrabrood competition is also an ecology well-suited to the evolution of cytoplasmic male killing (Hurst 1991; Hamilton 1993; Normark 2004a). Moreover, we have assumed that there is an asymmetry in which female-beneficial variants improve the likelihood of a mating pair winning a breeding opportunity (as it is competitiveness of females that determines this), while male-beneficial variants have no such effect. While this does adequately capture the ecology of many haplodiploid species, there are scenarios in which this assumption need not hold. For instance, males may have beneficial fitness effects upon their mates if there is paternal care, as in the case of the mud daubers (Brockmann 1980; Bragato Bergamaschi et al. 2015) and the solitary apid bee, Ceratina nigrolabiata (Mikát et al. 2019), or if sperm is a limiting factor on the rate of reproduction. Alternatively, males may also have deleterious fitness effects if they exhibit harming traits such as the traumatic insemination observed in some groups of pinworms (Adamson 1989).

In conclusion, we have explored how genetic and ecological asymmetries that characterize haplodiploid groups are expected to modulate sexual antagonism, and how these may, in turn, foment conflicts both between and within individuals over such traits. Exploring the consequences of these unusual genetic systems and life cycles has previously offered rich insights into sex allocation (Charnov 1982; West 2009), and thus, leveraging the natural diversity within these groups may also deepen our understanding of sexual antagonism and the evolution of sexual dimorphism. Gene expression studies increasingly look for sex-biased gene expression in such nonmodel and noneumendelian species, and our predictions will facilitate interpretation of these data, as well as identifying where future research effort may be most fruitfully focused. Finally, many of the species that reproduce through arrhenotoky or PGE are pests and parasites of humans, livestock, and crops, for example, the coffee borer beetle, hessian fly, head lice, and the citrus mealybug. Improved understanding of the evolutionary consequences of these unusual lifecycles and genetics, therefore, also has practical relevance in guiding our use of chemical, biological, and genetic controls.

\section{AUTHOR CONTRIBUTIONS}

T.J.H., A.G., and L.R. jointly designed the study, T.J.H. performed the analysis, and T.J.H., A.G., and L.R. wrote the manuscript.

\section{ACKNOWLEDGMENTS}

We thank B. Normark, J. Rayner, K. Stucky, S. Sturiale, and L. Yusuf, for helpful discussion.

\section{DATA ARCHIVING}

There is no data to be archived. 


\section{FUNDING}

T.J.H. is supported by a PhD scholarship funded by the School of Biology, University of St Andrews. A.G. is supported by a Natural Environment Research Council Independent Research Fellowship (Grant no. NE/K009524/1) and a European Research Council Consolidator (Grant no. 771387). L.R. is supported by funding from the European Research Council Starting Grant (PGErepo) and from the Dorothy Hodgkin Fellowship (DHF $\backslash \mathrm{R} 1 \backslash 180120)$.

\section{CONFLICT OF INTEREST}

The authors declare no conflict of interest.

\section{LITERATURE CITED}

Adamson, M. L. 1989. Evolutionary biology of the Oxyurida (Nematoda): biofacies of a haplodiploid taxon. Adv. Parasitol. 28:175-228.

Adamson, M. L., and D. Ludwig. 1993. Oedipal mating as a factor in sex allocation in haplodiploids. Philos. Trans. R. Soc. London. Ser. B Biol. Sci. 341:195-202.

Albert, A. Y. K., and S. P. Otto. 2005. Sexual selection can resolve sex-linked sexual antagonism. Science (80-.) 310:119-121.

Alpedrinha, J., S. A. West, and A. Gardner. 2013. Haplodiploidy and the evolution of eusociality: worker reproduction. Am. Nat. 182:421438.

Anderson, N., K. S. Jaron, C. N. Hodson, M. B. Couger, J. Ševčík, S. Pirro, L. Ross \& S. W. Roy 2020. Gene-rich X chromosomes implicate intragenomic conflict in the evolution of bizarre genetic systems. bioRxiv. https://doi.org/10.1101/2020.10.04.325340.

Arnqvist, G. 2011. Assortative mating by fitness and sexually antagonistic genetic variation. Evolution (N. Y.) 65:2111-2116.

Aron, S., L. de Menten, D. R. Van Bockstaele, S. M. Blank, and Y. Roisin. 2005. When hymenopteran males reinvented diploidy. Curr. Biol 15:824-827.

Bachtrog, D., J. E. Mank, C. L. Peichel, M. Kirkpatrick, S. P. Otto, T. L. Ashman, M. W. Hahn, J. Kitano, I. Mayrose, R. Ming, et al. 2014. Sex determination: why so many ways of doing it? PLoS Biol 12:1-13.

Bebbington, K., and T. G. G. Groothuis. 2021. Who listens to mother? A whole-family perspective on the evolution of maternal hormone allocation. Biol. Rev 96:1951-1968.

Benford, F. A. 1978. Fisher's theory of the sex ratio applied to the social hymenoptera. J. Theor. Biol 72:701-727.

Bitume, E. V., D. Bonte, O. Ronce, I. Olivieri, and C. M. Nieberding. 2014. Dispersal distance is influenced by parental and grand-parental density. Proc. R. Soc. B Biol. Sci 281:20141061.

Bragato Bergamaschi, A. C., J. da Costa Almeida, L. A. de Oliveira Campos, and M. A. del Lama. 2015. Sociogenetic structure in nests of the mud dauber wasp Trypoxylon (Trypargilum) albitarse (Hymenoptera: Crabronidae). Eur. J. Entomol 112:722-727.

Brockmann, H. J. 1980. Diversity in the nesting behavior of mud-daubers (Trypoxylon politum Say; Sphecidae). Florida Entomol 63:53.

Browne, L. B. 1922. Life-history of Melittobia acasta. Parasitology 14:350370.

Buchner, P. 1965. Endosymbiosis of animals with plant microorganisms. Interscience Publishers, New York.

Burt, A., and R. Trivers. 2006. Genes in conflict. Belknap Press, Cambridge, MA.

Charlesworth, B., J. A. Coyne, and N. H. Barton. 1987. The relative rates of evolution of sex chromosomes and autosomes. Am. Nat 130:113-146.

Charnov, E. L. 1978. Sex-ratio selection in eusocial hymenoptera. Am. Nat 112:317-326.
NJ.

Cheng, C., and M. Kirkpatrick. 2016. Sex-specific selection and sex-biased gene expression in humans and flies. PLoS Genet 12:1-18.

Clark, A. B. 1978. Sex ratio and local resource competition in a prosimian primate. Science (80-.) 201:163-165.

Connallon, T., and G. Matthews. 2019. Cross-sex genetic correlations for fitness and fitness components: connecting theoretical predictions to empirical patterns. Evol. Lett 3: 254-262.

Connallon, T., S. Sharma, and C. Olito. 2019. Evolutionary consequences of sex-specific selection in variable environments: four simple models reveal diverse evolutionary outcomes. Am. Nat 193:93-105.

Cook, J. M., S. G. Compton, E. A. Herre, and S. A. West. 1997. Alternative mating tactics and extreme male dimorphism in fig wasps. Proc. R. Soc. London. Ser. B Biol. Sci 264:747-754.

Crean, A. J., and R. Bonduriansky. 2014. What is a paternal effect? Trends Ecol. Evol 29:554-559.

Crow, J. F., and M. Kimura. 1970. An introduction to population genetics theory. Harper \& Row Publishers, New York, Evanston and London.

Dallai, R. 2000. Aberrant spermatogenesis and the peculiar mechanism of sex determination in symphypleonan Collembola. J. Hered 91:351-358.

Damiani, C., I. Ricci, E. Crotti, P. Rossi, A. Rizzi, P. Scuppa, F. Esposito, C. Bandi, D. Daffonchio, and G. Favia. 2008. Paternal transmission of symbiotic bacteria in malaria vectors. Curr. Biol 18:R1087-R1088.

Davies, N. G., and A. Gardner. 2014. Evolution of paternal care in diploid and haplodiploid populations. J. Evol. Biol 27:1012-1019.

Day, T., and R. Bonduriansky. 2004. Intralocus sexual conflict can drive the evolution of genomic imprinting. Genetics 167:1537-1546.

de la Filia, A. G., S. Andrewes, J. M. Clark, and L. Ross. 2018. The unusual reproductive system of head and body lice (Pediculus humanus). Med. Vet. Entomol 32:226-234.

de la Filia, A. G., S. A. Bain, and L. Ross. 2015. Haplodiploidy and the reproductive ecology of Arthropods. Curr. Opin. Insect Sci 9:36-43.

de la Filia, A. G., G. Fenn-Moltu, and L. Ross. 2019. No evidence for an intragenomic arms race under paternal genome elimination in Planococcus mealybugs. J. Evol. Biol 32:491-504.

de la Filia, A. G., A. J. Mongue, J. Dorrens, H. Lemon, D. R. Laetsch, and L. Ross. 2021. Males that silence their father's genes: genomic imprinting of a complete haploid genome. Mol. Biol. Evol. 28:2566-2581. https: //doi.org/10.1093/molbev/msab052

De Vooght, L., G. Caljon, J. Van Hees, and J. Van Den Abbeele. 2015. Paternal transmission of a secondary symbiont during mating in the viviparous tsetse fly. Mol. Biol. Evol 32:1977-1980.

de Vries, C., and H. Caswell. 2019. Selection in two-sex stage-structured populations: genetics, demography, and polymorphism. Theor. Popul. Biol. 130:160-169.

Ding, T., H. Chi, A. Gökçe, Y. Gao, and B. Zhang. 2018. Demographic analysis of arrhenotokous parthenogenesis and bisexual reproduction of Frankliniella occidentalis (Pergande) (Thysanoptera: Thripidae). Sci. Rep 8:3346.

Entwistle, P. F. 1964. Inbreeding and arrhenotoky in the ambrosia beetle Xyleborus compactus (Eich.) (Coleoptera: Scolytidae). Proc. R. Entomol. Soc. London. Ser. A, Gen. Entomol 39:83-88.

Flintham, E. O., V. Savolainen, and C. Mullon. 2021. Dispersal alters the nature and scope of sexually antagonistic variation. Am. Nat 197:543559.

Frank, S. A. 1986a. Hierarchical selection theory and sex ratios I. General solutions for structured populations. Theor. Popul. Biol 29:312-342.

. 1986b. The genetic value of sons and daughters. Heredity (Edinb) 56:351-354. 
2003. Genetic variation of polygenic characters and the evolution of genetic degeneracy. J. Evol. Biol 16:138-142.

Frank, S. A., and L. D. Hurst. 1996. Mitochondria and male disease. Nature 383:224-224.

Frank, S. A., and M. M. Patten. 2020. Sexual antagonism leads to a mosaic of X-autosome conflict. Evolution (N. Y.) 74:495-498.

Friberg Urban, Rice William R. 2015. Sexually Antagonistic Zygotic Drive: A New Form of Genetic Conflict between the Sex Chromosomes. Cold Spring Harbor Perspectives in Biology 7 (3): a017608. https://doi.org/ 10.1101/cshperspect.a017608

Fry, J. D. 2010. The genomic location of sexually antagonistic variation: some cautionary comments. Evolution (N. Y.) 64:1510-1516.

Gallun, R. L., and J. H. Hatchett. 1969. Genetic evidence of elimination of chromosomes in the Hessian Fly1,2. Ann. Entomol. Soc. Am 62:10951101.

Gardner, A. 2012. Evolution of maternal care in diploid and haplodiploid populations. J. Evol. Biol 25:1479-1486.

Gardner, A. 2010. Sex-biased dispersal of adults mediates the evolution of altruism among juveniles. J. Theor. Biol. 262:339-345. Elsevier.

Gardner, A., and L. Ross. 2011. The evolution of hermaphroditism by an infectious male-derived cell lineage: an inclusive-fitness analysis. Am. Nat 178:191-201.

-2014. Mating ecology explains patterns of genome elimination. Ecol. Lett 17:1602-1612.

Gardner, A., and F. Úbeda. 2017. The meaning of intragenomic conflict. Nat. Ecol. Evol 1:1807-1815.

Gemmell, N. J., V. J. Metcalf, and F. W. Allendorf. 2004. Mother's curse: the effect of mtDNA on individual fitness and population viability. Trends Ecol. Evol 19:238-244.

Glastad, K. M., B. G. Hunt, S. V. Yi, and M. A. D. Goodisman. 2014. Epigenetic inheritance and genome regulation: is DNA methylation linked to ploidy in haplodiploid insects? Proc. R. Soc. B Biol. Sci 281:20140411.

Grafen, A. 1986. Split sex ratios and the evolutionary origins of eusociality. J. Theor. Biol 122:95-121.

2006. A theory of Fisher's reproductive value. J. Math. Biol 53:1560 .

- 2014. Total reproductive values for females and for males in sexual diploids are not equal. J. Theor. Biol 359:233-235.

Haig, D. 1992. Intragenomic conflict and the evolution of eusociality. J. Theor. Biol 156:401-403.

- 1996. Placental hormones, genomic imprinting, and maternal-fetal communication. J. Evol. Biol 9:357-380.

- 2002. Genomic imprinting and kinship. Rutgers Univ. Press, NJ.

Hamilton, W. D. 1967. Extraordinary sex ratios. Science (80-.) 156:477-488.

- 1978. Evolution and diversity under bark. Pp. 154-175in L. Mound and N. Waloff, eds. Diversity of insect faunas. Blackwell Scientific Publishing, Oxford, England.

Hamilton, W. D. 1979. Wingless and fighting males in fig wasps and other insects. Sex. Sel. Reprod. Compet. Insects. https://doi.org/10.1016/ B978-0-12-108750-0.50011-2

-1993. Inbreeding in Egypt and in this book: a childish perspective. $i n \mathrm{~N}$. W. Thornhill, ed. The natural history of inbreeding and outbreeding: theoretical and empirical perspectives. Univ. of Chicago Press, Chicago, IL.

Harris, M. O., J. J. Stuart, M. Mohan, S. Nair, R. J. Lamb, and O. Rohfritsch. 2003. Grasses and gall midges: plant defense and insect adaptation. Annu. Rev. Entomol 48:549-577.

Harts, A. M. F., L. E. Schwanz, and H. Kokko. 2014. Demography can favour female-advantageous alleles. Proc. R. Soc. B Biol. Sci 281: 20140005.
Hatcher, M. J., and A. M. Dunn. 1995. Evolutionary consequences of cytoplasmically inherited feminizing factors. Philos. Trans. R. Soc. London. Ser. B Biol. Sci 348:445-456.

Hitchcock, T. J., and A. Gardner. 2020. A gene's-eye view of sexual antagonism. Proc. R. Soc. B Biol. Sci 287:20201633.

Hodson, C. N., P. T. Hamilton, D. Dilworth, C. J. Nelson, C. I. Curtis, and S. J. Perlman. 2017. Paternal genome elimination in liposcelis booklice (Insecta: Psocodea). Genetics 206:1091-1100.

Hodson, C. N., K. S. Jaron, S. Gerbi, and L. Ross. 2021. Evolution of generich germline restricted chromosomes in black-winged fungus gnats through introgression (Diptera: Sciaridae). bioRxiv. https://doi.org/10. 1101/2021.02.08.430288

Hodson, C. N., and L. Ross. 2021. Evolutionary perspectives on germlinerestricted chromosomes in flies (Diptera). Genome Biol. Evol 13: evab072.

Holman, L. 2014. Caste load and the evolution of reproductive skew. Am. Nat 183:84-95.

Hurst, G. D. D., and C. L. Frost. 2015. Reproductive parasitism: maternally inherited symbionts in a biparental world. Cold Spring Harb. Perspect. Biol 7:a017699.

Hurst, L. D. 1991. The incidences and evolution of cytoplasmic male killers. Proc. R. Soc. London. Ser. B Biol. Sci 244:91-99.

Irwin, A. J., and P. D. Taylor. 2001. Evolution of Altruism in stepping-stone populations with overlapping generations. Theor. Popul. Biol. 60:315325.

Iwasa, Y., and A. Pomiankowski. 1999. Sex specific X chromosome expression caused by genomic imprinting. J. Theor. Biol 197:487-495.

. 2001. The evolution of X-linked genomic imprinting. Genetics 158:1801-1809.

Jaquiéry, J., C. Rispe, D. Roze, F. Legeai, G. Le Trionnaire, S. Stoeckel, L. Mieuzet, C. Da Silva, J. Poulain, N. Prunier-Leterme, et al. 2013. Masculinization of the $\mathrm{X}$ chromosome in the pea aphid. PLoS Genet 9:e1003690.

Jaquiéry, J., J. -C. Simon, S. Robin, G. Richard, J. Peccoud, H. Boulain, F. Legeai, S. Tanguy, N. Prunier-Leterme, and G. Le Trionnaire. 2021. Masculinization of the $\mathrm{X}$-chromosome in aphid soma and gonads. bioRxiv. https://doi.org/10.1101/2021.08.13.453080

Johnstone, R. A., and M. A. Cant. 2008. Sex differences in dispersal and the evolution of helping and harming. Am. Nat 172:318-330.

. 2010. The evolution of menopause in cetaceans and humans: the role of demography. Proc. R. Soc. B Biol. Sci 277:3765-3771.

Jordal, B. H., R. A. Beaver, and L. R. Kirkendall. 2001. Breaking taboos in the tropics: incest promotes colonization by wood-boring beetles. Glob. Ecol. Biogeogr 10:345-357.

Jordan, C. Y., and T. Connallon. 2014. Sexually antagonistic polymorphism in simultaneous hermaphrodites. Evolution (N. Y) 68:3555-3569.

Kasimatis, K. R., P. L. Ralph, and P. C. Phillips. 2019. Limits to genomic divergence under sexually antagonistic selection. G3 (Bethesda) 9:38133824.

Kidwell, J. F., M. T. Clegg, F. M. Stewart, and T. Prout. 1977. Regions of stable equilibria for models of differential selection in the two sexes under random mating. Genetics 85:171-183.

Klein, K., H. Kokko, and H. ten Brink. 2021. Disentangling verbal arguments: intralocus sexual conflict in haplodiploids. Am. Nat. 198. https://doi. org/10.1086/716908

Korb, J., and D. K. Aanen. 2003. The evolution of uniparental transmission of fungal symbionts in fungus-growing termites (Macrotermitinae). Behav. Ecol. Sociobiol 53:65-71.

Kraaijeveld, K. 2009. Male genes with nowhere to hide; Sexual conflict in haplodiploids. Anim. Biol 59:403-415. 
Kuijper, B., N. Lane, and A. Pomiankowski. 2015. Can paternal leakage maintain sexually antagonistic polymorphism in the cytoplasm? J. Evol. Biol. 28:468-480. Wiley Online Library.

Mank, J. E. 2017. Population genetics of sexual conflict in the genomic era. Nat. Rev. Genet 18:721-730.

Marinosci, C., S. Magalhães, E. Macke, M. Navajas, D. Carbonell, C. Devaux, and I. Olivieri. 2015. Effects of host plant on life-history traits in the polyphagous spider mite Tetranychus urticae. Ecol. Evol 5:31513158.

Marshall, H., J. S. van Zweden, A. Van Geystelen, K. Benaets, F. Wäckers, E. B. Mallon, and T. Wenseleers. 2020. Parent of origin gene expression in the bumblebee, Bombus terrestris, supports Haig's kinship theory for the evolution of genomic imprinting. Evol. Lett 4:479-490.

McCulloch, J. B., and J. P. Owen. 2012. Arrhenotoky and oedipal mating in the northern fowl mite (Ornithonyssus sylviarum) (Acari: Gamasida: Macronyssidae). Parasit. Vectors 5:281.

Metz, C. W. 1938. Chromosome behavior, inheritance and sex determination in Sciara. Am. Nat 72:485-520.

Mikát, M., L. Janošík, K. Černá, E. Matoušková, J. Hadrava, V. Bureš, and J. Straka. 2019. Polyandrous bee provides extended offspring care biparentally as an alternative to monandry based eusociality. Proc. Natl. Acad. Sci 116:6238-6243.

Miller, P. M., S. Gavrilets, and W. R. Rice. 2006. Sexual conflict via maternaleffect genes in ZW species. Science (80-.) 312:73.

Mongue, A. J., S. Michaelides, O. Coombe, A. Tena, D. -S. Kim, B. B. Normark, A. Gardner, M. S. Hoddle, and L. Ross. 2021. Sex, males, and hermaphrodites in the scale insect Icerya purchasi. Evolution (N. Y.). https://doi.org/10.1111/evo.14233

Moran, N. A., and H. E. Dunbar. 2006. Sexual acquisition of beneficial symbionts in aphids. Proc. Natl. Acad. Sci 103:12803-12806.

Morris, M. R., D. Goedert, J. K. Abbott, D. M. Robinson \& O. Rios-Cardenas 2013. Intralocus tactical conflict and the evolution of alternative reproductive tactics. Pp. 447-478. Advances in the study behavior. Elsevier, Burlington, MA.

Mousseau, T. A., and H. Dingle. 1991. Maternal effects in insect life histories. Annu. Rev. Entomol 36:511-534.

Mousseau, T. A., and C. W. Fox. 1998. Maternal effects as adaptations. Oxford Univ. Press, Oxford, England.

Nagelkerke, C. J., and M. W. Sabelis. 1996. Hierarchical levels of spatial structure and their consequences for the evolution of sex allocation in mites and other arthropods. Am. Nat 148:16-39.

Nelson-Rees, W. A. 1960. A study of sex predetermination in the mealy bug Planococcus citri (Risso). J. Exp. Zool 144:111-137.

Normark, B. B. 2003. The evolution of alternative genetic systems in insects. Annu. Rev. Entomol 48:397-423.

- 2004a. Haplodiploidy as an outcome of coevolution between malekilling cytoplasmic elements and their hosts. Evolution (N. Y.) 58:790798.

. 2004b. The strange case of the armored scale insect and its bacteriome. PLoS Biol 2:e43.

- 2006. Perspective: maternal kin groups and the origins of asymmetric genetic systems-genomic imprinting, haplodiploidy, and parthenogenesis. Evolution (N. Y.) 60:631-642.

- 2009. Unusual gametic and genetic systems. Pp. 507-538in Sperm biology. Elsevier, Burlington, MA.

Oku, K., S. Yano, and A. Takafuji. 2003. Different maternal effects on diapause induction of tetranychid mites, Tetranychus urticae and T. kanzawai (Acari: Tetranychidae). Appl. Entomol. Zool 38:267270.

Orr, H. A., and S. P. Otto. 1994. Does diploidy increase the rate of adaptation? Genetics 136:1475-1480.
Owen, A. R. G. 1953. A genetical system admitting of two distinct stable equilibria under natural selection. Heredity (Edinb) 7:97-102.

Pamilo, P. 1979. Genic variation at sex-linked loci: quantification of regular selection models. Hereditas 91:129-133.

Parsons, P. A. 1961. The initial progress of new genes with viability differences between sexes and with sex linkage. Heredity (Edinb) 16:103107.

Patten, M. M. 2019. The X chromosome favors males under sexually antagonistic selection. Evolution (N. Y.) 73:84-91.

Patten, M. M., and D. Haig. 2009. Parental sex discrimination and intralocus sexual conflict. Biol. Lett 5:667-670.

Pen, I. 2006. When boys want to be girls: effects of mating system and dispersal on parent-offspring sex ratio conflict. Evol. Ecol. Res 8:103113.

Pennell, T. M., L. Holman, E. H. Morrow, and J. Field. 2018. Building a new research framework for social evolution: intralocus caste antagonism. Biol. Rev. 93:1251-1268.

Perlmutter, J. I., and S. R. Bordenstein. 2020. Microorganisms in the reproductive tissues of arthropods. Nat. Rev. Microbiol 18:97-111.

Poissant, J., A. J. Wilson, and D. W. Coltman. 2010. Sex-specific genetic variance and the evolution of sexual dimorphism: a systematic review of cross-sex genetic correlations. Evolution (N. Y.) 64:97-107.

Price, G. R. 1970. Selection and covariance. Nature 227:520-521.

Queller, D. C. 2003. Theory of genomic imprinting conflict in social insects. BMC Evol. Biol 3:15.

Queller, D. C., and J. E. Strassmann. 2002. The many selves of social insects. Science (80-.) 296:311-313.

Rand, D. M., A. G. Clark, and L. M. Kann. 2001. Sexually antagonistic cytonuclear fitness interactions in Drosophila melanogaster. Genetics 159:173-187. Oxford University Press.

Rasch, E. M., J. D. Cassidy, and R. C. King. 1977. Evidence for dosage compensation in parthenogenetic Hymenoptera. Chromosoma 59:323-340.

Rautiala, P., and A. Gardner. 2016. Intragenomic conflict over soldier allocation in polyembryonic parasitoid wasps. Am. Nat 187:E106-E115.

Rice, W. R. 1984. Sex chromosomes and the evolution of sexual dimorphism. Evolution (N. Y) 38:735.

Rice, W. R., S. Gavrilets, and U. Friberg. 2008. Sexually antagonistic "zygotic drive" of the sex chromosomes. PLoS Genet 4:e1000313.

Rieffel, S. M., and H. V. Crouse. 1966. The elimination and differentiation of chromosomes in the germ line of sciara. Chromosoma 19:231-276.

Rodrigues, L., M. Torralba Sáez, J. Alpedrinha, S. Lefèvre, M. Brengues, S. Magalhães, and A. B. Duncan. 2021. Consequences of population structure for sex allocation and sexual conflict. J. Evol. Biol. 34:525536.

Ronce, O., and D. Promislow. 2010. Kin competition, natal dispersal and the moulding of senescence by natural selection. Proc. R. Soc. B Biol. Sci 277:3659-3667.

Ross, L., E. J. Dealey, L. W. Beukeboom, and D. M. Shuker. 2011a. Temperature, age of mating and starvation determine the role of maternal effects on sex allocation in the mealybug Planococcus citri. Behav. Ecol. Sociobiol 65:909-919.

Ross, L., M. B. W. Langenhof, I. Pen, L. W. Beukeboom, S. A. West, and D. M. Shuker. 2010a. Sex allocation in a species with paternal genome elimination: the roles of crowding and female age in the mealybug Planococcus citri. Evol. Ecol. Res 12:89-104.

Ross, L., I. Pen, and D. M. Shuker. 2010b. Genomic conflict in scale insects: the causes and consequences of bizarre genetic systems. Biol. Rev. https://doi.org/10.1111/j.1469-185X.2010.00127.X

Ross, L., D. M. Shuker, B. B. Normark, and I. Pen. 2012. The role of endosymbionts in the evolution of haploid-male genetic systems in scale insects (Coccoidea). Ecol. Evol 2:1071-1081. 
Ross, L., D. M. Shuker, and I. Pen. 2011b. The evolution and suppression of male suicide under paternal genome elimination. Evolution (N. Y.) 65:554-563.

Rowe, L., S. F. Chenoweth, and A. F. Agrawal. 2018. The genomics of sexual conflict. Am. Nat 192:274-286.

Royer, M. 1975. Hermaphroditism in insects. Studies on Icerya purchasi. Pp. 135-145 in R. Reinboth, ed. Intersexuality in the animal kingdom. Springer Berlin Heidelberg, Berlin, Heidelberg.

Ruzicka, F., and T. Connallon. 2020. Is the X chromosome a hot spot for sexually antagonistic polymorphisms? Biases in current empirical tests of classical theory. Proc. R. Soc. B Biol. Sci 287:20201869.

Ruzicka Filip, Dutoit Ludovic, Czuppon Peter, Jordan Crispin Y., Li XiangYi, Olito Colin, Runemark Anna, Svensson Erik I., Yazdi Homa Papoli, Connallon Tim. 2020. The search for sexually antagonistic genes: Practical insights from studies of local adaptation and statistical genomics. Evolution Letters 4 (5): 398. -415. https://doi.org/10.1002/evl3.192

Schneider, M. V., L. W. Beukeboom, G. Driessen, L. Lapchin, C. Bernstein, and J. J. M. Van Alphen. 2002. Geographical distribution and genetic relatedness of sympatrical thelytokous and arrhenotokous populations of the parasitoid Venturia canescens (Hymenoptera). J. Evol. Biol 15:191200.

Scholes, D. R., A. V. Suarez, and K. N. Paige. 2013. Can endopolyploidy explain body size variation within and between castes in ants? Ecol. Evol 3:2128-2137.

Seger, J. 1983. Partial bivoltinism may cause alternating sex-ratio biases that favour eusociality. Nature 301:59-62.

Spennemann, D. H. R. 2019. Biology, ecology and distribution of the Date Stone Beetle, Coccotrypes dactyliperda (Coleoptera: Curculionidae). Zool. Middle East 65:163-182.

Taylor, P. D. 1981. Intra-sex and inter-sex sibling interactions as sex ratio determinants. Nature 291:64-66.

-1990. Allele-frequency change in a class-structured population. Am. Nat 135:95-106.
Tazzyman, S. J., and J. K. Abbott. 2015. Self-fertilization and inbreeding limit the scope for sexually antagonistic polymorphism. J. Evol. Biol 28:723729.

Trivers, R. 1972. Parental investment and sexual selection. Pp. 136-179 in Sexual selection and the descent of man. Aldine Publishing Company, Chicago.

. 1974. Parent-offspring conflict. Am. Zool 14:249-264.

Tuan, S. -J., Y. -H. Lin, C. -M. Yang, R. Atlihan, P. Saska, and H. Chi. 2016. Survival and reproductive strategies in two-spotted spider mites: demographic analysis of Arrhenotokous parthenogenesis of Tetranychus urticae (Acari: Tetranychidae). J. Econ. Entomol 109:502-509.

Varndell, N. P., and H. C. J. Godfray. 1996. Facultative adjustment of the sex ratio in an insect (Planococcus citri, Pseudococcoidae) with paternal genome loss. Evolution (N. Y.) 50:2100-2105.

Wade, M. J. 2014. Paradox of mother's curse and the maternally provisioned offspring microbiome. Cold Spring Harb. Perspect. Biol 6:a017541.

Watanabe, K., F. Yukuhiro, Y. Matsuura, T. Fukatsu, and H. Noda. 2014. Intrasperm vertical symbiont transmission. Proc. Natl. Acad. Sci 111:7433-7437.

Werren, J. H., and M. J. Hatcher. 2000. Maternal-zygotic gene conflict over sex determination: effects of inbreeding. Genetics 155:1469-1479.

West, S. 2009. Sex allocation. Princeton Univ. Press, NJ.

White, M. J. D. 1977. Animal cytology and evolution. CUP Archive.

Wild, G., and S. A. West. 2009. Genomic imprinting and sex allocation. Am. Nat 173:E1-E14.

Wright, S. 1931. Evolution in Mendelian populations. Genetics 16:97159.

Yeh, A. Y. -C., and A. Gardner. 2012. A general ploidy model for the evolution of helping in viscous populations. J. Theor. Biol 304:297303.

Associate Editor: T. Connallon Handling Editor: T. Chapman

\section{Supporting Information}

Additional supporting information may be found online in the Supporting Information section at the end of the article.

Supplementary material 